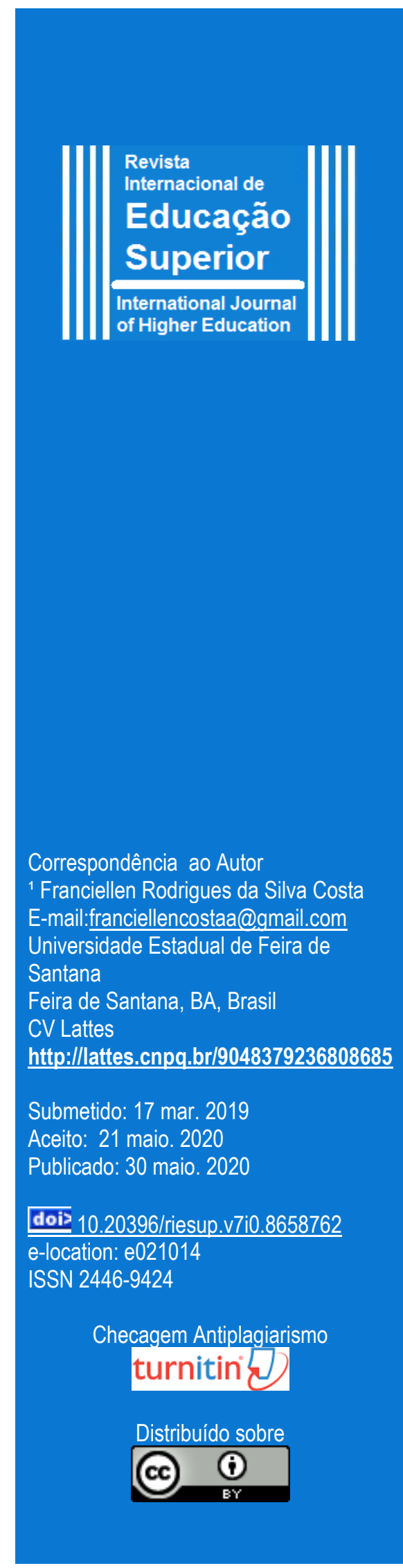

\title{
A Trajetória dos Agentes Sociais no Ensino Superior do Estado do Paraná
}

Franciellen Rodrigues da Silva Costa 1 https://orcid.org/0000-0003-3381-1179

Álvaro Lorencini Júnior (D. https://orcid.org/0000-0001-9365-2312

Leila Inês Follmann Freiret ${ }^{3}$ iD https://orcid.org/0000-0002-6679-411X

${ }^{1}$ Universidade Estadual de Feira de Santana, ${ }^{2}$ Universidade Estadual de Londrina 3Universidade Estadual de Ponta Grossa

\section{RESUMO}

A pesquisa trata-se de um estudo a fim de caracterizar o capital cultural no estado institucionalizado dos professores universitários da área de Educação Química do Paraná, evidenciando a trajetória de formação acadêmica dos agentes, por meio de seus indicadores escolares. A investigação caracterizou-se como uma pesquisa qualitativa do tipo documental, pois utilizou-se de documentos, como os currículos Lattes disponíveis na plataforma do Conselho Nacional de Desenvolvimento Científico e Tecnológico $(\mathrm{CNPq})$, para mensurar informações na constituição de dados. Com o estudo documental, buscou-se mapear os dados extraídos dos documentos, com o intuito de aferir os determinantes escolares, como o nível, a área, o local e o período de formação dos agentes sociais atuantes no Ensino de Química dentro do campo acadêmico. Nesse sentido, pudemos compreender como os determinantes escolares influenciaram no capital cultural dos agentes do subcampo da Educação Química no campo acadêmico. Para a análise dos dados, utilizou-se da metodologia de Análise de Conteúdo de Bardin (2010), baseadas nas ideias de Bourdieu (2007, 2017b), referente ao capital cultural. Os resultados apontaram para um subcampo, constituído por mestres e doutores, formados principalmente, no estado do Paraná, com formações nem sempre lineares ao campo científico. Desse modo, devido às lutas exercidas para estruturação de um campo científico e preocupações acerca do objeto de investigação, utilizaram-se de seu capital cultural institucionalizado para incorporarem-se de disposições constitutivas, geradas durantes os espaços de formação acadêmica.

\section{PALAVRAS-CHAVE}

Educação superior. Formação acadêmica. Pós-graduação. Ensino de ciências. 


\title{
The Trajectory of Social Agents in Higher Education in the State of Paraná
}

\begin{abstract}
The research is a study designed to characterize the cultural capital in the institutionalized state of the university professors in the area of Chemical Education in the state of Paraná, presenting the trajectory of academic training of agents, through their school indicators. The investigation was characterized as a qualitative research of documentary type, since it used documents, such as the Lattes curriculums available on the CNPQ (National Council for Scientific and Technological Development) platform, to measure the information in the constitution of data. With the documentary study, we sought to map the data extracted from the documents, in order to assess the school determinants, such as the level, area, place, and period of training of social agents working in the Teaching of Chemistry within the academic field. In this sense, we were able to understand how the school determinants influenced the cultural capital of the agents of the Chemical Education subfield in the academic field. For data analysis, we used Bardin's Content Analysis methodology (2010), based on the ideas of Bourdieu (2007, 2017b), referring to cultural capital. The results pointed to a subfield, constituted of masters and doctors, trained mainly in the state of Paraná, with formations not always linear to the scientific field. Thus, due to the struggles exercised to structure a scientific field and concerns about the object of investigation, they used their institutionalized cultural capital to incorporate constitutive dispositions, generated during academic training spaces.
\end{abstract}

\section{KEYWORDS}

Higher education. Degrees. Postgraduate courses. Science education.

\section{La Trayectoria de los Agentes Sociales en la Educación Superior en el Estado de Paraná}

\section{RESUMEN}

La investigación es un estudio diseñado para investigar la trayectoria de la formación académica de docentes pertenecientes al subcampo de Educación Química (EQ) de los cursos de Licenciatura en Química en instituciones públicas de educación superior en el estado de Paraná. La investigación se caracterizó como una investigación cualitativa, de tipo documental, ya que utilizaba documentos, como los currículos Lattes disponibles en la plataforma $\mathrm{CNPq}$, para medir información en la construcción de datos. Con el estudio bibliométrico, buscamos mapear los datos extraídos de los documentos, a fin de evaluar el nivel, área, lugar y período de capacitación de los agentes sociales que trabajan en la Enseñanza de Química dentro del campo académico. Para el análisis de datos, se utilizó la metodología de análisis de contenido de Bardin (2010), con la elaboración de categorías establecidas a priori basadas en las ideas de Bourdieu (2004, 2017a), en referencia al capital cultural. Los resultados mostraron que el subcampo EQ consiste en maestros y doctores, entrenados principalmente en los estados de Paraná, Santa Catarina y São Paulo, con formaciones que no siempre son lineales al campo científico. Además, los resultados confirmaron la expansión del subcampo EQ en Paraná, lo que se indica por el crecimiento de agentes como formaciones específicas para trabajar en los cursos de Licenciatura en Química, lo cual es una indicación para la consolidación y constitución del área como campo de estudio.

\section{PALABRAS CLAVE}

Enseñanza superior. Título académico. Curso postuniversitario. Enseñanza de las ciencias. 


\section{Introdução}

Quando se fala a respeito da Educação Superior, retratada aqui neste artigo como campo acadêmico, é preciso pensar em quais agentes sociais fazem parte deste universo. $\mathrm{O}$ campo acadêmico, na perspectiva de Bourdieu (2017b), é constituído por professores, pesquisadores, estudantes de pós-graduação, bolsistas de iniciação científica, acadêmicos de graduação, enfim, todos os indivíduos dispostos a fazer parte de um jogo de interesses próprios e coletivos na academia.

É importante ressaltar que tal campo, já mencionado, agrega seus departamentos, colegiados, coordenadores, reitores, diretores, e outras funções e lugares atribuídos ao capital universitário, para exercer a função de representantes em cargos e posições. Dentro dos departamentos $^{1}$, referentes às áreas de conhecimentos específicos, os professores universitários são dispostos em subáreas distintas, com a função de ministrar aulas dentro dos currículos dos cursos estabelecidos pela construção conjunta de um campo e realizar pesquisas dentro de diferentes linhas temáticas.

Num departamento de Química, por exemplo, os professores universitários são distribuídos, geralmente, entre as áreas de Inorgânica, Analítica, Orgânica, Físico-Química e Ensino - podendo, estas áreas, serem ampliadas conforme sua organização departamental sendo elas as responsáveis pela formação de graduados no campo acadêmico. Desse modo, salienta-se que esses professores universitários atuam em diferentes cursos, sem limitarem-se apenas aos cursos de Química, seja na habilitação de Licenciatura ou Bacharelado. Neste trabalho, o foco estará nos agentes que fazem parte do subcampo da Educação Química (EQ) responsável pelo Ensino de Química, uma das subáreas responsáveis pela formação de futuros professores de Química para Educação Básica.

O profissional da área de Ensino de Química faz parte de um campo científico da Educação em Ciências, isto é, trata-se de uma área ${ }^{2}$ intitulada de Educação Química. Para fazer parte deste subcampo, o profissional deve ser formado no curso de Química, e pósgraduado em Ensino de Ciências, Educação, ou áreas afins. Entretanto, esta trajetória nem sempre é linear e contínua, visto que são várias estratégias, inclusive, para adentrar e permanecer neste subcampo, abrangendo as de formação.

\footnotetext{
${ }^{1}$ A designação departamental é uma das formas de organização do campo acadêmico, já que existem outras. Por exemplo, no estado do Paraná temos universidades que estão organizadas em torno de centros (p.e. UNICENTRO), outras em departamentos (UEPG, UEL, UEM) e outras por cursos (UNIOESTE), e ainda existem ainda aquelas que se organizam em torno de faculdades e setores.

${ }^{2}$ A palavra subcampo designada para falar da Educação em Química tenta evidenciar esta área como uma parte de um campo maior, como o campo acadêmico. Mas, que de forma geral este subcampo congrega especificidades de um campo, a ponto de nomeá-la e diferenciá-la de outros campos acadêmicos específicos.
} 
As estratégias ou jogos nem sempre são explícitos, mas construídos em longos períodos, com o propósito de proteger as ideias, delimitar as metodologias, aumentar seus volumes de capitais, agregar reconhecimento etc. Além disso, nem todos os agentes sociais constroem sua trajetória de formação acadêmica com base nos critérios estabelecidos pelo campo, mas conseguem ser reconhecidos pelos seus pares como indivíduos pertencentes, devido à sua dedicação e participação na área.

Os agentes sociais delimitados às discussões deste trabalho são os professores universitários, atuantes nos cursos de Licenciatura em Química das instituições de ensino superior (IES) públicas do estado do Paraná. Os mesmos são considerados também educadores e químicos, responsáveis por constituírem suas espécies de capitais e poderes que regem o campo acadêmico. No entanto, as discussões que se referem às condições do acúmulo de capitais (econômicos, sociais, simbólico) serão frutos de um trabalho mais amplo. Neste momento, as discussões abordam a caracterização do subcampo de professores universitários da área de Educação Química no estado do Paraná, por meio de seu capital cultural, evidenciando a trajetória de formação acadêmica dos agentes, através de seus indicadores escolares, apresentados no currículo Lattes ${ }^{3}$, na forma de titulações, instituições, período de formação etc. (BOURDIEU, 2004, 2007, HEY, 2008).

\section{O Campo Acadêmico Para a Área de Educação Química}

O campo acadêmico refere-se ao uso do mecanismo institucional, assegurado pelo Estado brasileiro, no qual garante a produção, reprodução e circulação de produtos acadêmicos. No Brasil, este espaço envolve universidades e instituições financiadoras - em destaque a Coordenação de Aperfeiçoamento de Pessoal de Nível Superior (CAPES) e o Conselho Nacional de Desenvolvimento Científico e Tecnológico (CNPq) - que, com apoio destas instituições, pode, entre outras disposições, "criar as associações de pós-graduações e pesquisa em diversas áreas do conhecimento, produzir periódicos científicos e eventos no país, tanto para os pesquisadores nacionais quanto os estrangeiros, formar centros e grupos de pesquisa e celebrar acordos institucionais para intercâmbios científicos com centros internacionais" (HEY, 2008, p. 16).

Como visto, o espaço acadêmico requer agentes sociais, ou melhor, comunidades capazes de tomar estas ações possíveis. O termo 'comunidade científica', emprestado das ideias de Thomas Kuhn, teve, segundo Bourdieu (2017a, p. 29), a função de enunciar a formação de uma comunidade fechada com problemas definidos, a qual se utiliza de métodos

\footnotetext{
${ }^{3} \mathrm{O}$ currículo Lattes é uma incumbência de cada pesquisador, exibido na Plataforma Lattes, do Conselho Nacional de Desenvolvimento Científico e Tecnológico - CNPq. "O Currículo Lattes se tornou um padrão nacional no registro da vida pregressa e atual dos estudantes e pesquisadores do país, e é hoje adotado pela maioria das instituições de fomento, universidades e institutos de pesquisa do País. Por sua riqueza de informações e sua crescente confiabilidade e abrangência, se tornou elemento indispensável e compulsório à análise de mérito e competência dos pleitos de financiamentos na área de ciência e tecnologia." (vide: http://lattes.cnpq.br/)
} 
designados para aquele campo, servindo como um paradigma disciplinar, isto é, "um estado da realização científica que é aceite por uma fracção importante dos cientistas e que tende a impor-se a todos os outros”. Entretanto, segundo Bourdieu (2017a), é necessário romper com as ideias pressupostas de comunidade científica, que preveem um conceito de ciência pura, totalmente autônoma e seguindo lógicas internas, introduzindo a ideia de campo. Dessa forma, ao ampliar os olhares, compreende-se que os grupos não são unificados ou os homogêneos, mas formados por um lócus de relações entre sujeitos com interesses individuais para jogar o jogo de um universo coletivo, ou seja, uma prática social legitimada.

Por conseguinte, a ideia de campo trata-se "de forças dotadas de uma estrutura e também um espaço de conflitos pela manutenção ou transformação desse campo de forças" (BOURDIEU, 2017a, p. 52). Sendo assim, o campo de forças ocorre pela relação entre os diferentes agentes e os poderes propriamente constituídos de diferentes capitais, determinando uma estrutura de posições dentro do campo científico. Tais forças também são estendidas a outros campos, a exemplo da estrutura do campo acadêmico que mediante seu crescimento populacional estudantil, necessitou do aumento de um corpo de professores dentro das universidades com formações específicas e condicionou aos agentes deste campo uma forma de capital cultural institucionalizado para "Ihes assegurar uma carreira burocrática e rendimentos regulares" (BOURDIEU, 2017b, p. 63). Desse modo, ocupa-se uma posição dominante, sobre outros setores menos institucionalizados.

Logo, o espaço acadêmico, segundo Hey (2008, p. 102) “produz e é produzido por agentes reais - de carne e osso - dotados de capitais específicos, evidenciados nas propriedades levantadas de cada um, os quais permitem sua atuação nele”. Então, sendo este, um espaço de lutas, repleto de enfrentamentos entre os pesquisadores já dotados de diferentes capitais, visa-se também conservar ou transformar as relações de força (HEY, 2008).

A intenção é pensar no espaço acadêmico como um território constituído de diferentes componentes, entre eles os agentes sociais, agentes estes que, neste trabalho, são os professores universitários do subcampo da Educação Química. No campo acadêmico da área de Química, os educadores são formados em menores quantidades se comparados com outros mestres e doutores das outras áreas da Química (Analítica, Físico-química, Orgânica, Inorgânica) (SCHNETZLER, 2002). Posto isto, apesar dos dados do relatório da CAPES (2019) apontarem para o crescimento de programas de pós-graduação na área de Ensino (181), nas diversas modalidades (mestrado acadêmico, mestrado profissional, doutorado acadêmico e doutorado profissional), sabe-se que a área de Ensino atende não apenas educadores químicos, estendendo-se também aos físicos, biólogos e matemáticos; e todos os outros que compõe este campo científico (BRASIL, 2011).

A inserção destes agentes sociais nos cursos de pós-graduação, além de promover as especializações e o domínio conceitual, possibilita aos indivíduos a circulação em espaços sociais destinados à apropriação de habitus do campo. Neste momento, os agentes aprendem as estratégias estabelecidas para adquirir as diferentes formas de capitais e beneficiar-se por eles. Aos recém-chegados que conseguem enxergar os poderes envolvidos e apropriar-se deles, o prestígio e o reconhecimento é alcançado em menos tempo. 
É neste universo que os agentes criam seu espaço para a produção acadêmica, considerado também um espaço de lutas, uma arena onde este jogo da concorrência e da competição busca alcançar diferentes posições na estrutura do campo, objetivando agregar ainda mais capital e poder. Dessa maneira, sua estrutura é construída sobre a base de poderes, na intenção de descrever a lógica das lutas e definir a hierarquia no campo. À vista disso, ressalta-se que campos distintos tendem a instituir padrões específicos, como formas de relação dentro do campo, condições de ingressos etc., funcionando como meios de auxiliar o processo de reprodução social.

A estrutura do campo ainda possibilita a outorga de posições desiguais, em que alguns pesquisadores estão em destaque, por haver dominantes e dominados. Quanto maior for a quantidade de capital de um determinado agente, mais ele se destacará em relação aos outros membros e, consequentemente, haverá um sistema de classificação, responsável por fazer o 'nome do pesquisador' perante o campo.

As posições são construídas ao longo de sua trajetória profissional, por diferentes capitais (simbólico, social, cultural), os quais determinam, entre tantas coisas, a quantidade de publicações, a participação e/ou liderança em grupos de pesquisa, as diversas titulações, os cargos de administração universitária, a presença em eventos e congressos, a indicação para comissões científicas, a colaboração em bancas de qualificação e defesa, etc.

De acordo com Hey (2008, p.67), este sistema de classificação do grupo dominante "estabelece as classificações dos trabalhos que devem ser considerados relevantes, sérios, interessantes, ou melhor, que devem ser legitimados ou não". Assim, a hierarquia existente, permite compreender o porquê dos novos membros que adentram ao campo; terem a necessidade de citar os pesquisadores renomados, visto que é "sua baixa posição hierárquica que exige isso" (HEY, 2008, p. 67).

Segundo Hey (2008, p. 67) "a ausência de citações nominais é a forma mais acabada de censura”. Não ser citado por outros pesquisadores, é a falta de reconhecimento entre os pares, e esta ausência não caracteriza o trabalho do indivíduo como 'bom ou mau, mas sim aceito ou não aceito' pelo universo de pertencimento daqueles que ocupam posições semelhantes. Esta situação caracteriza-se como uma estratégia dos recém-chegados que buscam a aceitação dos dominantes, sendo esta admissão não expressa de forma verbal, e sim pela citação nominal de outros pesquisadores em textos científicos.

Quando entendem o sentido do jogo dentro do campo acadêmico, os futuros pesquisadores tendem a começar sua trajetória desde a graduação, em grupos de pesquisa, facilitando sua participação nos processos seletivos de pós-graduação. Adentrar a este meio já conhecendo seu funcionamento e suas regras, pode dar condições de conservar as ideias e interesses do grupo dominante existente e possibilitar ao novo membro do campo aproximarse deste grupo. Alguns processos de seleção da pós-graduação enfatizam mais as habilidades de expressar conhecimentos produzidos na pesquisa por meio de publicações do que propriamente reconhecer o domínio do conteúdo específico. 
Os novos pesquisadores ingressam em um meio onde já existem normas e regras a serem seguidas, não estando em suas mãos mudar o jogo, mas aprender a jogar este jogo, requerendo uma dedicação para adquirir novos conhecimentos. Logo, expressar-se na forma de produtos acadêmicos e ser reconhecido por estes resultados, trata-se de um investimento pessoal, que somente o próprio agente pode fazer. Por isso, ao adentrar no campo acadêmico, os pesquisadores acabam por aderir "[...] os gostos ou preferências acadêmicas [...] o envolvimento com diversos ambientes sociais que constituem a vida acadêmica, tais como as instituições de produção e a circulação científica" (HEY, 2008, p. 103).

Desta forma, entende-se que o campo acadêmico tem diversas disputas e poderes envolvidos e, a cada campo científico, cabem os seus. A Educação Química constitui-se como subcampo dentro de um campo acadêmico, com as mesmas características do campo. São grupos de cientistas, pesquisadores, professores, estudantes de pós-graduação, distribuídos em diferentes linhas temáticas de estudos, grupos de pesquisas, cargos e posições acadêmicas e políticas, comissões de revistas e eventos etc.

Na área de Educação Química, os interesses de investigação são atribuídos pelos grupos dominantes e expressos - em formas de linhas temáticas para submissão de trabalhos em eventos, seções e eixos temáticos em periódicos, linhas de pesquisas em programas de pós-graduação etc. - na condição de conservar suas ideias e legitimar suas ações. Algumas linhas são reconhecidas pelos pares - Formação de Professores, Ensino e Aprendizagem, Linguagem e Cognição, História, Filosofia e Sociologia da Ciência, Tecnologias da Informação e Comunicação, Currículo e Avaliação, Diversidade e Inclusão etc. - outras surgem de suas especificidades e teóricos selecionados pelos grupos. A intenção no presente artigo não é apresentar todas estas linhas, mas entender que dentro de um subcampo como a Educação Química, existem ainda outros desdobramentos em partes menores e interesses mais específicos.

São estes interesses provenientes de grupos cada vez mais especializados que movem o jogo para legitimar seus estudos. Em que, por mais que alguns agentes se dediquem às mesmas linhas temáticas, dentro destas, pode haver interesses comuns e interesses específicos, como as referências e metodologias empregadas. Por isso, ao olhar para estes campos e/ou subcampos, as suas posições serão medidas pelos poderes construídos pelo volume de capital individual e coletivo. Sendo estes capitais, distribuídos pelo capital econômico, capital social, capital cultural e capital simbólico.

Deste modo, este trabalho busca olhar para um destes capitais, intitulado segundo Bourdieu (2007), como capital cultural, que se apresenta de três formas- o estado incorporado, o estado objetivado e o estado institucionalizado- indicadas pelo autor no artigo 'Os três estados do capital cultural' publicado na obra Escritos da Educação. O primeiro, capital cultural no estado incorporado, está ligado ao corpo, no qual se pressupõe a incorporação, onde o indivíduo precisa dedicar tempo e investimento em si próprio, não podendo ser transmitido ou adquirido por outra pessoa. A acumulação demanda uma longa duração, a fim de tornar este capital como parte integrante do agente (habitus), sendo este

\begin{tabular}{l|c|c|c|c|c|}
\hline () Rev. Inter. Educ. Sup. & Campinas, SP & v.7 & $1-28$ & $\mathrm{e} 021014$ & 2021
\end{tabular} 
conceito muito utilizado por Bourdieu (1983, p. 65) para designar "sistema de disposições duráveis e transponíveis que, integrando experiências passadas, funciona a cada momento como uma matriz de percepções, apreciações e ações".

O capital cultural, em seu estado objetivado, segundo Bourdieu (2007), configura-se como a posse de bens materiais, os quais representam a cultura dominante em forma de obras científicas (artigos, livros etc), bibliotecas, laboratórios, museus, aos quais necessitam de capital cultural incorporado para apreciá-los, decifrá-los ou elaborá-los. Assim, o capital objetivado só existe (BOURDIEU, 2007, p.74) "como capital ativo e atuante, de forma material e simbólica, na condição de ser apropriado pelos agentes e utilizado como arma e objeto das lutas", onde em um espaço acadêmico, os professores universitários obtêm benefícios proporcionais ao domínio desse capital objetivado.

E em seu estado institucionalizado, Bourdieu (2007) afirma que o capital se manifesta como atestado de reconhecimento institucional de competências culturais adquiridas, em forma de diplomas, titulações, certificados etc. As certificações no campo acadêmico garantem aos agentes sociais o reconhecimento institucional, permitindo estabelecer formas de classificação e critérios para adentrar ao campo. Além disso, as titulações asseguram um retorno financeiro pelas retribuições direcionadas a cada nível de ensino (titulações) dentro do espaço acadêmico. São bens construídos desde as suas primeiras lições escolares, que percorrem toda a sua formação acadêmica e que continuam a ser construídos.

A tendência em adquirir as certificações parte da necessidade de credenciamento educacional para atuar no campo acadêmico (Ensino Superior), visto que, o campo exige cada vez mais especialistas em determinadas áreas, e na área de Educação Química, não é diferente. Tal busca por especializações pode ser evidenciada ao traçar a trajetória de formação acadêmica dos agentes, por meio de seus determinantes escolares, desde a inserção no campo acadêmico a partir de referentes graduações.

Para a análise da trajetória, deve-se traçar um mapa de localização do campo intelectual a ser investigado, neste caso referentes ao campo acadêmico pertencente às IES públicas do Estado do Paraná, e olhar para marcos distintos na trajetória de formação dos agentes sociais. Logo, ela será o resultado construído de um sistema de informações pertinentes e individuais dos sujeitos analisados. Em suma, "perseguir uma trajetória significa acompanhar o desenrolar histórico de grupos sociais concretos em um espaço social definido por esses mesmos grupos em suas batalhas pela definição dos limites e da legitimidade dentro do campo em que se inserem" (MONTAGNER, 2007, p.18).

\section{Metodologia}

A pesquisa caracteriza-se como uma pesquisa qualitativa do tipo documental, pois se utiliza como instrumento de coleta de dados- os documentos ainda não tratados analiticamente ou referenciados bibliograficamente (OLIVEIRA, 2014). Para a constituição do corpus da 
pesquisa, utilizaram-se diferentes técnicas e instrumentos de coleta de dados, entre eles: currículo Lattes dos agentes pertencentes as IES do estado do Paraná, formulário eletrônico e levantamento documental de informações em sites públicos.

O primeiro passo foi encontrar quais são os sujeitos pertencentes ao campo acadêmico (Ensino Superior) de Educação Química no Estado do Paraná, no ano de 2018. Decidiu-se realizar um levantamento das Instituições de Ensino Superior (IES), utilizando como critério os cursos presenciais da área de Química no Cadastro Nacional de Cursos e Instituições de Educação Superior (Cadastro e-MEC). A busca no site do e-MEC somente permite a seleção da opção de Química, sem delimitar as distintas habilitações, por isso, optou-se em solicitar, junto ao órgão do Conselho Regional de Química (CRQ IX ${ }^{4}$ ), a lista dos cursos cadastrados em suas bases, a fim de aferir estas diferenças e selecionar as IES que ofertam os cursos de Química, com a habilitação em licenciatura, em instituições públicas. Para triangular as informações e devido a respectiva representatividade, foi enviado um formulário eletrônico (Google forms) a diferentes agentes pertencentes a este subcampo da Educação Química.

A busca ainda serviu para quantificar a oferta de cursos de Licenciatura nas IES, visto que algumas instituições, como Universidade Tecnológica Federal do Paraná (UTFPR), Universidade Estadual do Paraná (UNESPAR) e Instituto Federal do Paraná (IFPR) são distribuídos em campus de cidades diferentes. Neste caso, identificou-se 11 IES públicas, que ofertam um total de 21 cursos de Licenciatura, assim distribuídos: IFPR - Campus Cascavel, Irati, Jacarezinho, Palmas, Paranavaí, Pitanga e Umuarama; UTFPR - Campus Apucarana, Campo Mourão, Curitiba, Londrina e Medianeira; Universidade Estadual de Londrina (UEL); Universidade Estadual de Maringá (UEM); Universidade Estadual de Ponta Grossa (UEPG); Universidade do Centro Oeste (UNICENTRO) - Guarapuava; Universidade Estadual do Oeste do Paraná (UNIOESTE) - Campus Toledo; UNESPAR - Campus União da Vitória; Universidade Federal do Paraná (UFPR); Universidade Federal Fronteira Sul (UFFS) Campus Realeza e Universidade Federal de Integração Latino-Americana (UNILA). Às coordenações de curso destas universidades públicas, foi enviado um e-mail, solicitando a indicação dos professores de cada curso e IES que atuavam na área de Ensino de Química.

O cruzamento de informações devido ao contato via e-mail com os coordenadores dos cursos de licenciatura em Química e o formulário eletrônico (enviado aos docentes indicados pelas coordenações como sendo da área de Ensino de Química), possibilitou a identificação de 62 agentes sociais do subcampo da Educação Química atuantes nas IES públicas do Estado do Paraná. Nem todas as IES com cursos de Licenciatura em Química têm agentes sociais da área de Educação Química. Em posse da lista com os nomes dos professores universitários, partiu-se para a análise dos currículos Lattes, disponíveis na plataforma do CNPq, a qual consistiu como fonte de dados, devido às informações disponíveis para uso público.

\footnotetext{
4 Conselho Regional de Química - 9a região. Os CRQ's são entidades pertencentes à esfera estadual e constituem a manifestação regional do Conselho Federal de Química (CFQ), sendo responsáveis pela físcalização do exercício das profissões da área tecnológica em âmbito regional, como a regulamentação de conteúdos mínimos aos cursos de Química, e aferir suas atribuições profissionais. Disponível na Resolução Normativa $\mathrm{n}^{\circ} 36$, de 25 de abril de 1974.

\begin{tabular}{l|l|l|l|l|l|}
\hline (C) Rev. Inter. Educ. Sup. & Campinas, SP & v.7 & $1-28$ & e021014 & 2021
\end{tabular}
}


A primeira análise no Lattes possibilitou extrair critérios mensuráveis, com condições de quantificá-los pela análise qualitativa dentro de indicadores pré-estabelecidos. Então, partir disso, foi criada uma planilha de dados alfanuméricos para cada professor analisado, conforme o Quadro 1.

Quadro 1. Os indicadores nos currículos Lattes dos agentes da EQ no estado do PR

\begin{tabular}{|c|c|c|c|c|c|c|}
\hline $\begin{array}{c}\text { Nome } \\
\text { do } \\
\text { agente }\end{array}$ & $\begin{array}{c}\text { Vínculo } \\
\text { IES }\end{array}$ & Nível de ensino & Instituição & $\begin{array}{c}\text { Período de } \\
\text { formação }\end{array}$ & $\begin{array}{c}\text { Local de } \\
\text { formação }\end{array}$ & $\begin{array}{c}\text { Programa de } \\
\text { pós-graduação }\end{array}$ \\
\hline \multirow{2}{*}{ P1 } & & Graduação & & & & \\
\cline { 2 - 7 } & & Especialização & & & & \\
\cline { 2 - 7 } & & Mestrado & & & & \\
\cline { 2 - 7 } & & Doutorado & & & & \\
\hline
\end{tabular}

Fonte: os autores

Foi utilizado, neste conjunto, a metodologia de Análise de Conteúdo (BAR0DIN, 2010), a partir das informações construídas pelos indicadores, permitindo agrupá-las em categorias construídas a priori. As categorias foram geradas com a finalidade de conhecer a trajetória de formação dos professores universitários, mediante as certificações expressas por eles em seus currículos Lattes, sendo elas: nível de formação, área de formação, local de formação e período de formação. A compreensão das informações construídas é apresentada em conjuntos com as discussões baseadas nas ideias de Bourdieu (2017a) e Hey (2008), no entendimento sobre como os determinantes escolares, responsáveis pela formação acadêmica do sujeito, conduzem suas posições no campo acadêmico.

Assim sendo, o trabalho teve como objetivo de caracterizar o capital cultural no estado institucionalizado dos professores universitários da área de Educação Química no estado do Paraná, evidenciando a trajetória de formação acadêmica dos agentes por meio de seus indicadores escolares. Logo, oportunizou-se refletir sobre o seguinte questionamento: Como os determinantes escolares influenciaram no capital cultural dos agentes do subcampo da Educação Química no campo acadêmico?

\section{Resultado e Discussão}

O trabalho dentro do campo acadêmico exige titulações para exercer as funções dentro deste espaço. Os agentes sociais buscam suas formações em diferentes instituições e espaços ao longo de sua trajetória acadêmica, até de fato conseguirem concluir seus objetivos acadêmicos. As formas de adentrar a este domínio provêm de diferentes condições, a exemplo de processos seletivos, concursos públicos, grupos de pesquisa, programas de pós-graduação dentre outros. No que tange à exemplificação mencionada anteriormente, os processos seletivos um dos mais utilizados para seleção de novos membros para o campo, tanto para exercer a função de docência nas universidades, quanto para ingressar na pesquisa ou extensão universitária. 
Enfim, todos os agentes pertencentes ao campo acadêmico trilharam seus próprios caminhos, com trajetórias diferentes, mas também com interesses comuns para estar à frente da área de Educação Química em IES públicas. No caso do estado do Paraná, estes agentes estão distribuídos nos cursos de Licenciatura em Química, totalizando 62 agentes sociais, distribuídos entre 45 doutores, cinco mestres e 12 doutorandos. O levantamento dos professores universitários é apresentado no Gráfico 1, conforme seu vínculo de trabalho nas IES, sendo que, em duas instituições localizadas na cidade de Paranavaí e Pitanga, não se identificou professores que atuam na EQ.

Gráfico 1. Os agentes sociais da EQ nas IES públicas do estado do Paraná

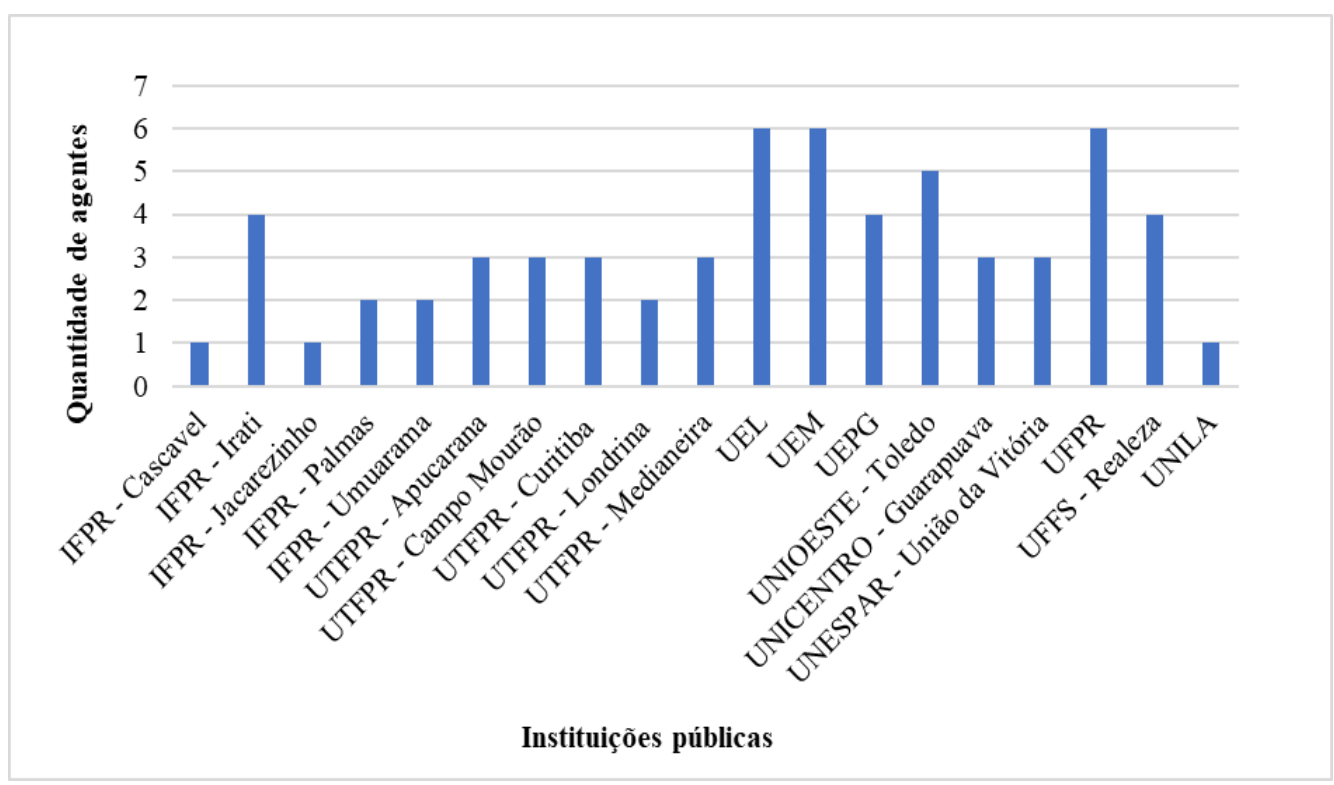

Fonte: os autores, com base nos dados dos currículos Lattes dos agentes da EQ

Observa-se uma maior quantidade de professores universitários dedicados a área de Educação Química na UEM, UEL e UFPR. Uma das justificativas pode estar relacionada com o surgimento dos cursos de Licenciatura em Química, sendo estes os mais antigos do estado do Paraná, com isso, a quantidade de concursos realizados para contratação de professores atuantes na área de EQ abrangeu mais estas IES. Além disso, por serem cursos mais longevos, em algum momento, professores com outras formações acadêmicas assumiram o ensino antes da contratação de professores com formação específica, e estes continuaram a dedicar-se a área de ensino nestas instituições.

\section{Nível de Formação}

Os cursos de graduação cursados pelos agentes foram diversos (Química, Filosofia, Pedagogia, Matemática, Física, Filosofia, Biologia). Sendo assim, o enfoque na trajetória do professor, após esta formação inicial, pode mostrar outros percursos que o possibilitaram adentrar ao campo acadêmico como docentes atuantes em cursos de Licenciatura em Química dentro da área de Educação Química. 
Para os níveis de formação, conforme o Gráfico 2, identifica-se que os agentes sociais pertencentes ao subcampo da Educação Química são mestres em sua totalidade (100\%),-e doutores em grande maioria (91,9\%). Estes dados refletem os possíveis critérios para os processos de seleção e concursos, os quais exigem a formação mínima de mestre como prérequisito.

Gráfico 2. Formação acadêmica dos agentes em diferentes níveis de ensino

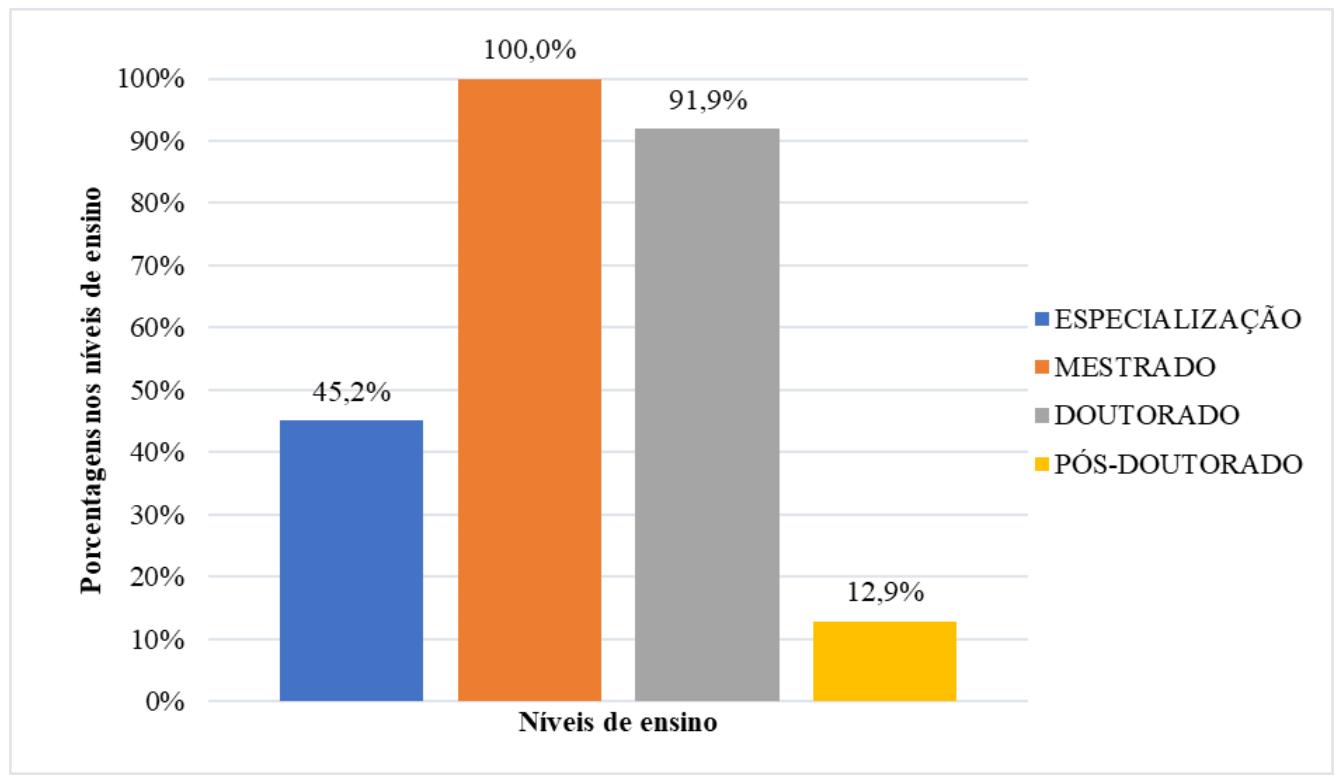

Fonte: os autores, com base nos dados dos currículos Lattes dos agentes da EQ

Atualmente, são 53 professores concursados e 9 professores colaboradores com contratos temporários, atuantes no subcampo da Educação Química. Embasado nos dados citados, salienta-se que pela análise do currículo não é possível inferir se todos estes profissionais participaram de processos de seleção específicos para a área de Ensino de Química, visto que, a área, por ser recente, teve a dedicação de outros professores, com formação na área da Química, para sua consolidação.

O pós-doutorado apresenta a menor quantidade de agentes formados nesta modalidade (12,9\%). Uma das justificativas pode estar atribuída a ausência de retribuição econômica para os agentes pertencentes no campo acadêmico. Outra possibilidade para este número baixo é o que será apresentado na análise do tempo de conclusão do doutorado (temos um volume considerável de recém-doutores). Entretanto, nota-se um grande número de professores com especializações, como mostra o Gráfico 3: 
Gráfico 3. Quantidade de especialização por agentes sociais da EQ

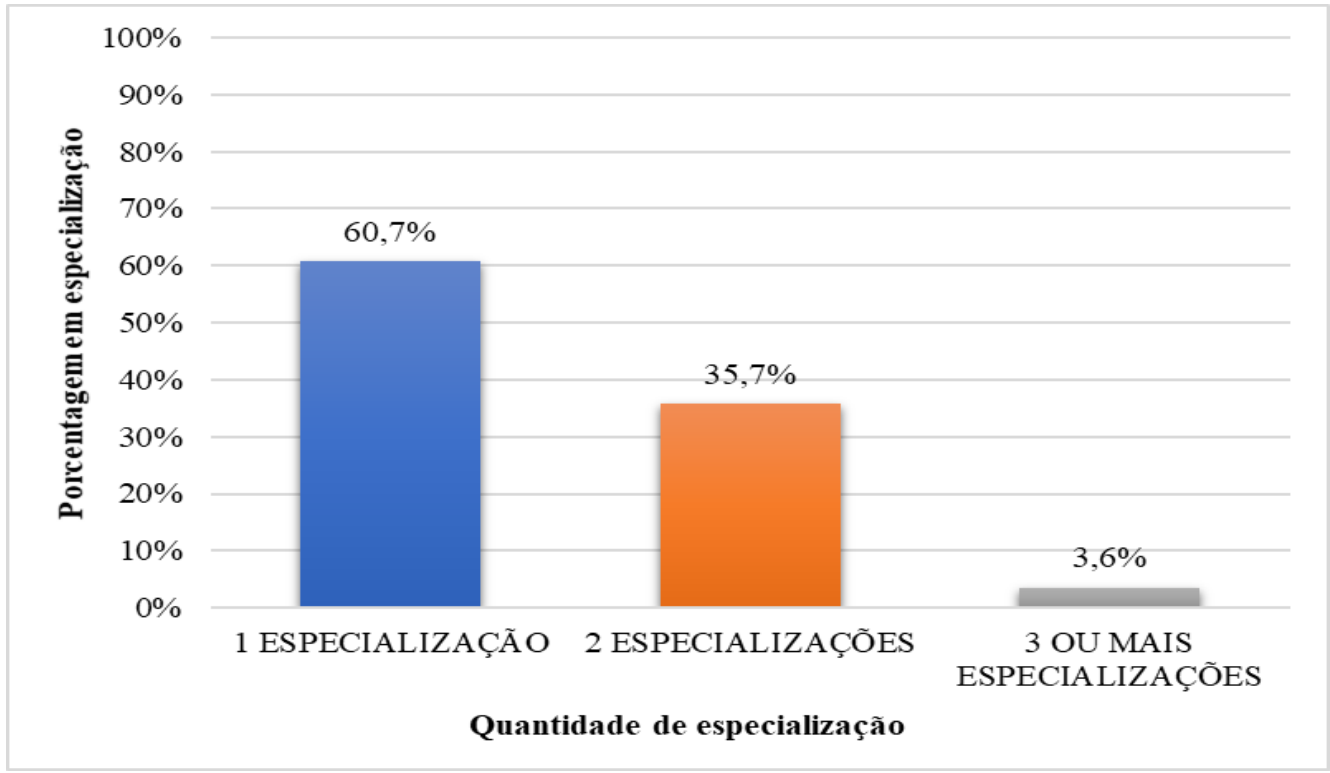

Fonte: os autores, com base nos dados dos currículos Lattes dos agentes da EQ

$\mathrm{Na}$ análise do Gráfico 3, identifica-se que dos 62 profissionais, 60,7\% tem apenas uma especialização, outros $35,7 \%$ tem pelo menos duas especializações, e 3,6\% tem três ou mais especializações. Os primeiros processos de seleção no estado do Paraná, não estabeleciam o mestrado como pré-requisito, sendo substituído pela especialização na área de Ensino. Esta situação, fez com que alguns agentes buscassem a especialização para ingressar no campo universitário. Outra justificativa para a quantidade de especializações $(45,2 \%)$ está em que muitos agentes não optaram no primeiro momento pelo campo acadêmico-e buscaram ou traçaram sua trajetória pela educação básica. Sendo que, os concursos de Processo Seletivo Simplificado (PSS) da Secretaria de Estado da Educação do Paraná (SEED) pelo Núcleo Regional de Educação (NRE) ${ }^{5}$ do PR em suas inscrições, utilizam-se das certificações (especializações) lato sensu como requisitos nas pontuações para alcançar melhores posições na disputa do processo de seleção.

A trajetória nos diferentes espaços públicos e privados nas IES, pode ser vista no Gráfico 4. No caso das especializações, tanto nas instituições privadas $(43,6 \%)$, como nas instituições públicas $(56,4 \%)$ os dados mostram-se próximos, e isto pode estar associado a busca destas formações, como apontando anteriormente, por meio de certificações em cursos lato sensu devido aos custos e prazos menores, além de uma maior flexibilidade nos horários por serem disponibilizados principalmente na forma de Ensino a Distância (EAD).

\footnotetext{
5 São macro(ou micro)regiões do estado com gerenciamento das ações escolares, aos quais compete a coordenação, a orientação, o controle, a adoção, a aplicação, o acompanhamento e a avaliação da execução de medidas destinadas a manter e aprimorar o funcionamento do ensino fundamental e médio, regular, ensino de jovens e adultos e ensino especial, nas unidades escolares das redes estadual, municipal e particular, observadas as políticas da Secretaria. Disponível em: http://www.nre.seed.pr.gov.br/
} 
Gráfico 4: Formação acadêmica dos agentes sociais em IES públicas e privadas

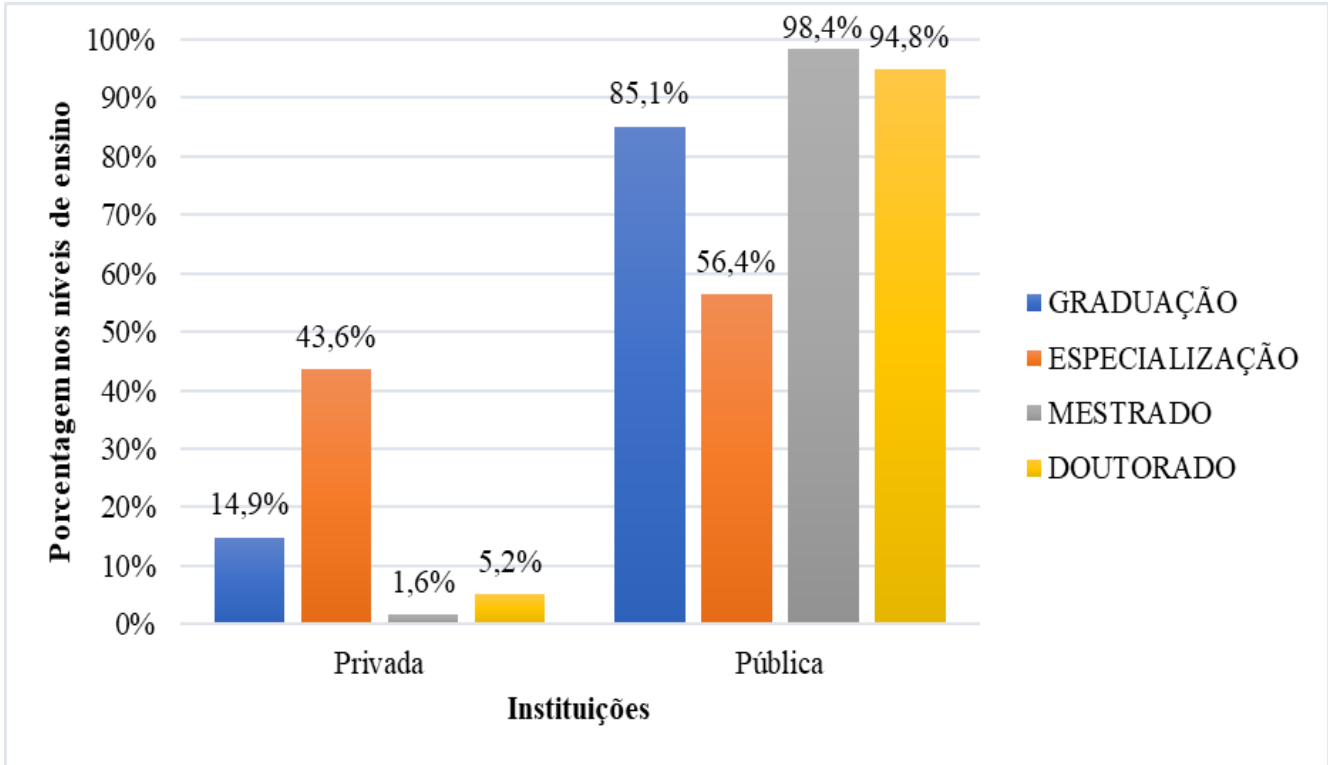

Fonte: Fonte: os autores, com base nos dados dos currículos Lattes dos agentes da EQ

Outra informação perceptível pela análise do Gráfico 4, configura-se na maior amostragem de agentes com trajetórias de formação em IES públicas, principalmente quando olha-se para os níveis de graduação, mestrado e doutorado. Os egressos da graduação, muitas vezes já criam sua relação com a pesquisa durante sua formação inicial (iniciação científica, iniciação à docência, monitoria, etc.) e selecionam os programas das IES em que seus orientadores estão vinculados, devido as relações de trabalho já construídas. Além disso, esta busca estende-se à seleção de programas e cursos de pós-graduação com as melhores avaliações da CAPES, devido aos investimentos relacionados a pesquisa e bolsas de estudo, além de haver o interesse dos agentes iniciantes em começar a trilhar sua trajetória acadêmica de pesquisa perto dos pares com uma representatividade já estabelecida no campo.

Com isso, a busca pelas determinantes escolares faz parte do poder acadêmico "que é fundado principalmente no controle dos instrumentos de reprodução do corpo professoral" (BOURDIEU, 2017b), os quais apesar do volume de capital como forma de agregar seu reconhecimento e posição no meio acadêmico, as titulações tornam-se requisitos mínimos adentrar ao campo. Desta forma, segundo Hey (2008, p.90), a busca por certificações dos agentes de uma forma simplista trata-se de um "fenômeno manifesto, já que todos os pesquisadores passam por este percurso para entrar na carreira acadêmica". Mas que de uma forma mais ampla, pode apurar os ganhos simbólicos decorrentes, uma vez que no seu interior, "o agente poderá utilizar a sua posição como vantagem e como ganho em outros espaços sociais" Hey (2008, p. 102), como a participação em órgãos para propostas de políticas públicas, aprovação de currículos de cursos, e até mesmo elaboração de materiais didáticos legitimados pelo seu reconhecimento. 


\section{2. Área de Formação na Pós-graduação}

Os agentes sociais do subcampo da Educação Química, hoje formados dentro dos cursos de Licenciatura em Química e nos cursos e/ou programas de pós-graduações na área de Ensino/Educação de Ciências de Matemática, nem sempre obedeceram a esta linearidade na formação. Pela análise realizada, são percebidas as áreas de formação dentro da trajetória dos professores universitários atuantes no campo acadêmico da Educação Química no Paraná, as quais são distintas, conforme apresentado no Gráfico 5.

Gráfico 5. As áreas de formação dos agentes na pós-graduação

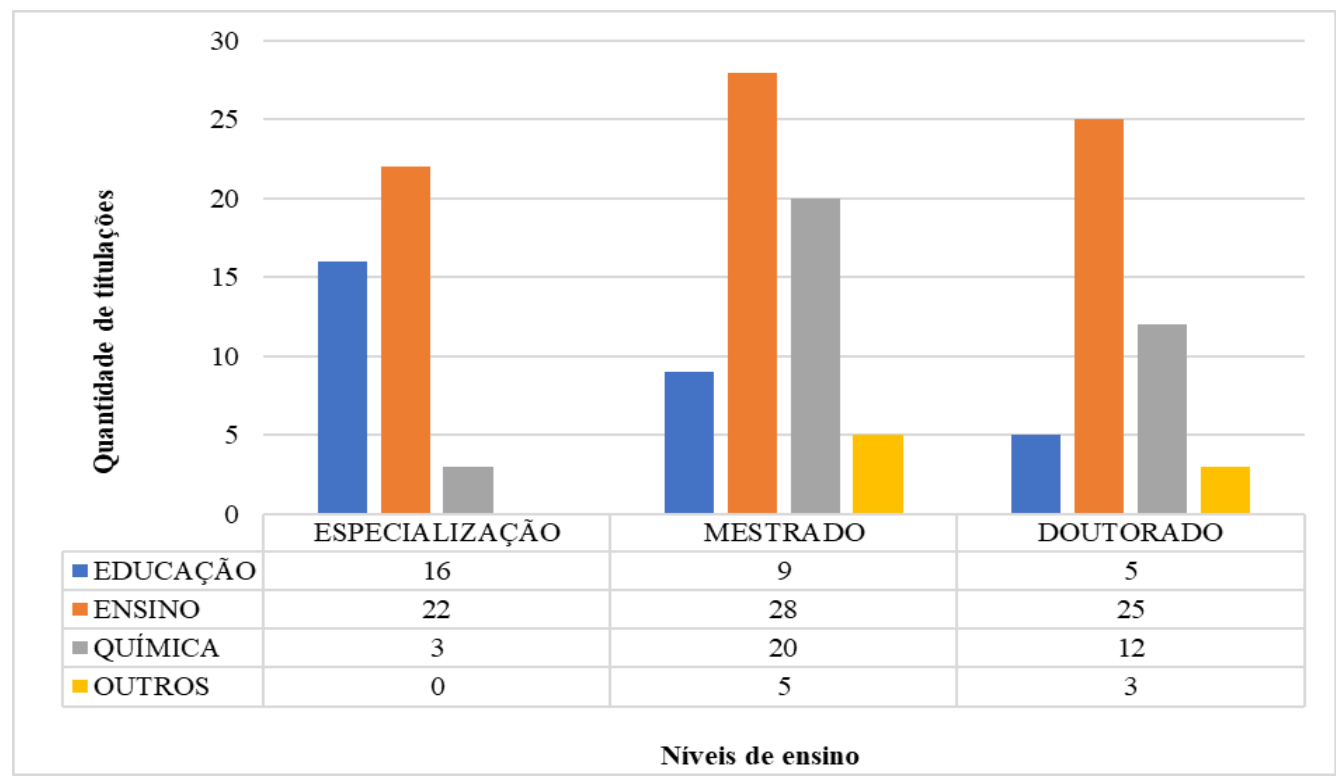

Fonte: os autores, com base nos dados dos currículos Lattes dos agentes da EQ

Na análise das pós-graduações lato sensu e stricto sensu, a utilização dos termos Educação, Ensino, Química, Outros - serviram para distinguir as diferentes áreas encontradas no Lattes. As palavras como Ensino e Educação, apesar de alguns usarem como sinônimos, têm um diferencial, quando se trata de pesquisa, especialmente, ao referir-se a cursos e programas de pós-graduação os quais também pertencem a diferentes áreas de avaliação da CAPES. Atualmente, os programas destinados a formar os agentes para subcampo da Educação Química estão classificados pela área de avaliação da CAPES (2017) como 'Ensino', dentro da grande área 'Multidisciplinar'. Esta área de ensino (área 46) foi criada em 2011 pela portaria 83/2011, incorporando todos os programas do antigo campo de Ensino de Ciências e Matemática, criada em 2000 (CAPES, 2017).

Ainda na análise do Gráfico 5, percebe-se que os professores universitários do estado do Paraná, tem um quantitativo maior de titulações acadêmicas nos níveis de mestrado e doutorado na área de 'Ensino', seguida da área de Química e Educação, sendo alguns formados em outras áreas, como por exemplo, a Engenharia. No 'Ensino', o destaque está na busca pelas especializações, visto que, estas certificações são realizadas em um percurso de tempo menor, em diversas instituições públicas e privadas, como maior alcance aos sujeitos interessados por esta formação. 
Pela análise, nota-se que a maioria dos agentes tem diferentes níveis de formação (mestrado, doutorado) dentro da área de 'Ensino'. No caso do mestrado, a quantidade de títulos (28) nesta área da pós-graduação não está distante da área de Química (20), sendo que no nível de doutorado esta discrepância é mais evidente. Estes dados podem indicar as mudanças dos agentes pelas áreas de formação quando terminam o mestrado e adentram ao doutorado. Visto que, há agentes que ingressam no mestrado na área de Química, e por vivenciar na docência universitária e/ou em outros espaços sociais relações com o subcampo da Educação Química, mudam o foco de sua formação ao dar continuidade em seus estudos no doutorado.

Deste modo, os dados indicam que o campo acadêmico da Educação Química no estado do Paraná é constituído de formações heterogêneas, influenciadas pelo avanço no número de cursos de Licenciatura em Química nas universidades e, consequentemente, na necessidade de docentes com formações específicas. Quanto ao aspecto explanado anteriormente, a ausência de profissionais com a devida formação, em uma determinada época, resultou na contratação de profissionais advindos de outras graduações. No entanto, a partir do momento em que houve a ampliação dos programas de pós-graduação e, consequentemente, formações específicas, o campo começou a se estruturar, denominando-se "de estudo", devido a materialização de um mesmo objeto de investigação. Com isso, o subcampo da Educação Química passa a constituir-se e estrutura-se pela formação de profissionais dentro de tais objetivos, pelos quais compreende-se que "a posição de cada agente nesta estrutura, ou melhor, o peso de cada um para formar essa estrutura, e ao mesmo tempo suportá-la, depende de todos os outros pesquisadores, bem como de todos os pontos do espaço e das relações entre todos os pontos" (HEY, 2008, p.80). Evidenciando que, o campo não existe pela sua individualidade, mas pela estruturação das pequenas partes, retratado aqui pelos agentes, para formar-se o coletivo de forças e lutas.

Em recente pesquisa Massi, Carvalho e Giordan (2020) investigaram a formação dos docentes, orientadores de pós-graduação stricto sensu do campo Ensino no país e apontaram que os programas de pós-graduação "une o grupo em torno de objetos comuns, por outro ela mascara fortes distinções" (2020, p.10). Desse modo, as próprias disparidades, pela ausência de critérios comuns, dificultam entender a área de Ensino como um campo, visto que "é quase impossível identificar um capital específico, um objeto de disputa comum entre agentes e demandas tão distintas". Essas características distintas da grande área de ensino não se aplicam todas à Educação Química, em que o objeto de disputa é comum, embora haja diferença na trajetória de formação em nível de pós-graduação, ainda existe uma maioria que tem o mesmo foco.

\section{Local de Formação}

$\mathrm{Na}$ análise dos currículos Lattes, aferiu-se as diferentes regiões do Brasil escolhidas pelos agentes para as suas formações nos diferentes níveis de ensino, apresentado no Gráfico 6. A grande parte dos professores são formados no estado do Paraná (35,3\%), seguidos de São Paulo (25,5\%), Rio Grande do Sul (9,8\%) e Santa Catarina (7,8\%), com menor

\begin{tabular}{l|l|l|l|l|l} 
(C) Rev. Inter. Educ. Sup. & Campinas, SP & v.7 & $1-28$ & e021014 & 2021 \\
\hline
\end{tabular}


quantidade na região Nordeste e Centro-Oeste do país. A escolha pelas instituições nos devidos estados pode envolver diferentes situações, como: proximidade de familiares, avaliações dos cursos e programas, no entanto, estas informações não são explícitas no Lattes, ficando sujeitas as interpretações diversas.

Gráfico 6. Local de formação dos agentes do EQ

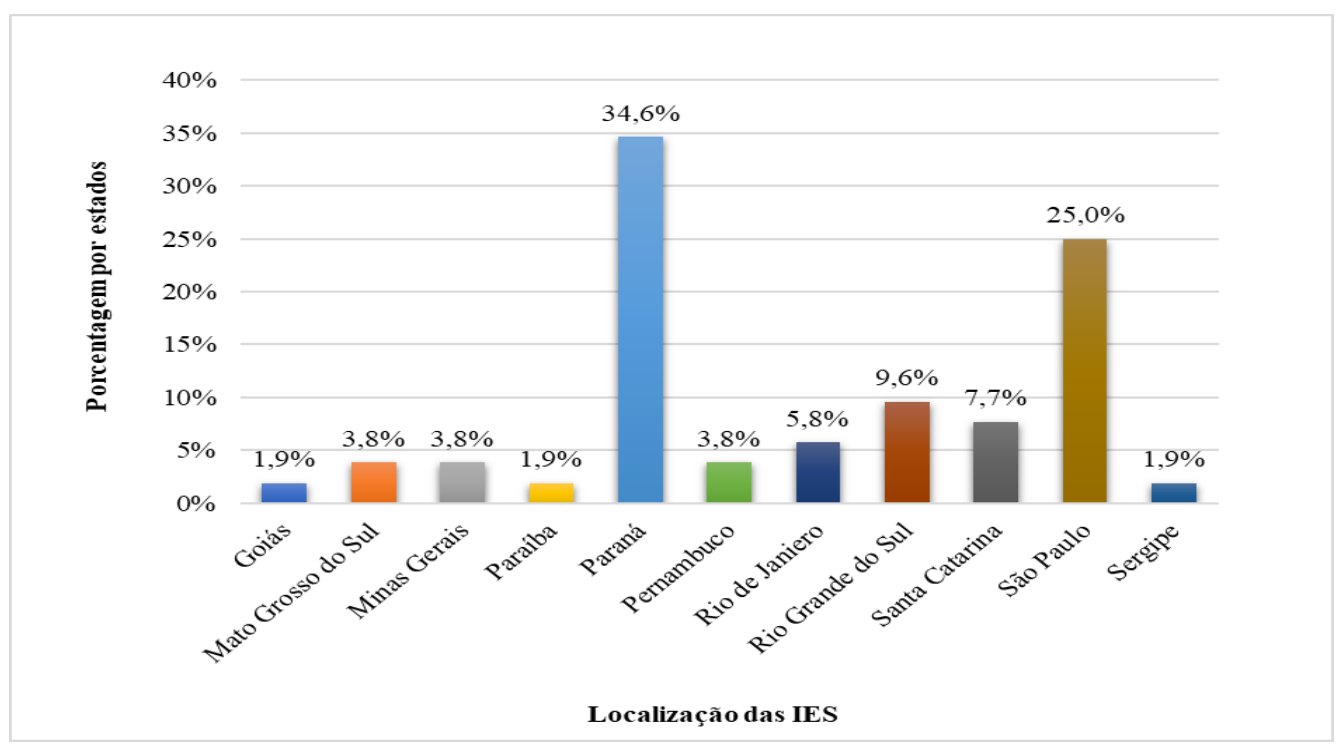

Fonte: os autores, com base nos dados dos currículos Lattes dos agentes da EQ

Ao olhar especificamente para o estado do Paraná, pelo Gráfico 7, é possível identificar as IES públicas e privadas destinadas à trajetória de formação acadêmica dos agentes ao campo acadêmico. Algumas universidades identificadas no Lattes dos professores trazem seus antigos nomes, é o caso do Centro Federal de Educação Tecnológica do Paraná (CEFET), que pela lei 11.184/2005, sancionada no governo do ex-presidente Luiz Inácio Lula da Silva, transformou esta instituição em UTFPR.

Gráfico 7. Formação dos agentes em instituições do estado do PR

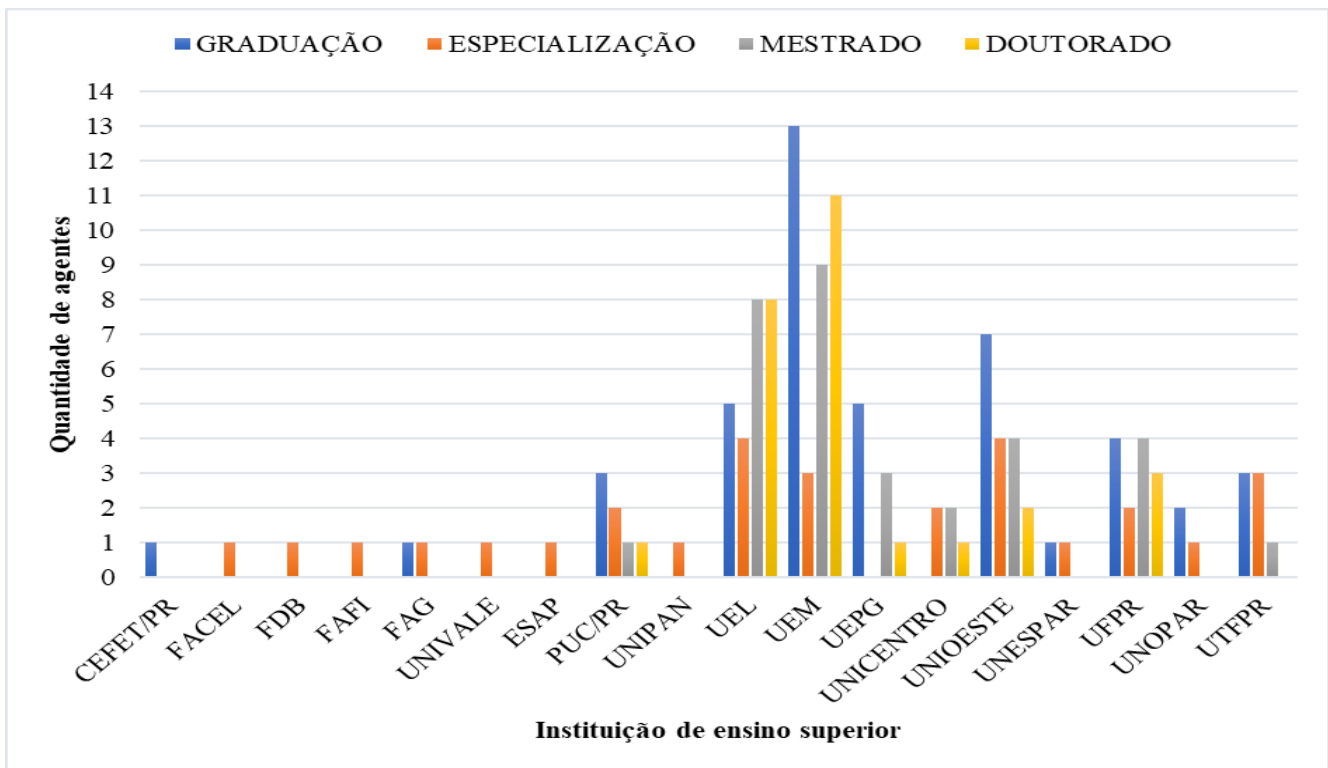

Fonte: os autores, com base nos dados dos currículos Lattes dos agentes da EQ 
Ainda pela análise do Gráfico 7, identifica-se que os agentes têm suas graduações distribuídas entre IES públicas e privadas, com seu maior índice de formandos, nas universidades estaduais (UEM, UEL, UNIOESTE, UEPG) e federais (UFPR, UTFPR). Com o destaque para o curso de Licenciatura em Química da UEM, por ser um dos mais antigos em relação a sua criação, $1970^{6}$. Outra justificativa pode estar atribuída a forte identidade do curso de Licenciatura na formação de professores de química, pelo envolvimento em grupos de pesquisa e extensão e políticas públicas (PIBID) com enfoque para Ensino de Química.

No caso da formação em nível de doutorado, a maioria dos agentes são formados no programa de pós-graduação em Educação para Ciências e Matemática (PCM) na UEM e no programa de Ensino de Ciências e Educação Matemática (PECEM) da UEL, na área de Ensino, sendo 11 e 8 egressos, respectivamente. Os programas da área 'Ensino (Área 46)' destinados à formação dos professores universitários para o Ensino de Química, estão alocados dentro da 'Grande Área - Multidisciplinar'. A área foi criada em 6 de junho pela portaria CAPES 83/2011, incorporando todos os programas de pós-graduações da antiga área de Ensino de Ciências e Matemática. Desse modo, no último relatório da CAPES (2017b), o crescente número de programas (157) e docentes (2.602) na área- tem enfatizado a dimensão deste campo de estudo no país, e enfatizado este crescimento também por regiões, como é caso da região Sul que fica atrás (em quantidade de programas) apenas da região Sudeste.

No caso do Paraná, os programas de pós-graduação apresentados no Quadro 1, conforme as informações disponíveis na Plataforma Sucupira (cursos avaliados e reconhecidos), estão distribuídos entre mestrado (M) e doutorado (D), na modalidade acadêmica e profissional. As avaliações dos programas de pós-graduação disponíveis para apuramento público realizado por outros pares (comissão de especialistas da área de Ensino) são organizadas pela diretoria de avaliação da Coordenação de Aperfeiçoamento de Pessoas de Nível Superior (CAPES), com base nas informações anuais registradas na Plataforma Sucupira. Sendo atribuída uma nota aos programas, como "notas 3 (regular), 4 (bom) e 5 (muito bom), e destes últimos se destacam programas excelentes, com notas 6 e 7, que constituem referências para as Áreas" (CAPES, 2017b, p.3).

\footnotetext{
6 O Curso de Licenciatura Plena em Química da Universidade Estadual de Maringá foi criado em 1970, autorizado pela Resolução no 01/70-COU, de 26 de novembro deste mesmo ano. Com a criação do Curso de Ciências (Resolução no 30/74 - CFE), o Curso de Química foi interrompido entre 1977 a 1979, sendo reativado em 1979. Disponível em: http://www.dqi.uem.br/graduacao
} 
Quadro 1. Os programas de pós-graduação da área de 'Ensino' do Estado do Paraná

\begin{tabular}{|c|c|c|c|c|}
\hline Instituição & Localização & Programa de pós-graduação & Nível & Nota \\
\hline \multicolumn{5}{|c|}{ PROGRAMAS ACADÊMICOS } \\
\hline UEL & Londrina & $\begin{array}{c}\text { Ensino de Ciências e } \\
\text { Educação Matemática } \\
\text { (PECEM) }\end{array}$ & $(\mathrm{M} / \mathrm{D})$ & 7 \\
\hline UEM & Maringá & $\begin{array}{c}\text { Educação para Ciências e a } \\
\text { Matemática (PCM) }\end{array}$ & $(\mathrm{M} / \mathrm{D})$ & 4 \\
\hline UFPR & Curitiba & $\begin{array}{l}\text { Educação em Ciências e em } \\
\text { Matemática (PPGECM) }\end{array}$ & $(\mathrm{M} / \mathrm{D})$ & 4 \\
\hline UNIOESTE & Cascavel & $\begin{array}{c}\text { Educação em Ciências e } \\
\text { Educação Matemática } \\
\text { (PPGECEM) }\end{array}$ & $(\mathrm{M} / \mathrm{D})$ & 4 \\
\hline UNIOESTE & Foz do Iguaçu & Ensino (PPGEn) & $(\mathrm{M})$ & 4 \\
\hline UTFPR & Ponta Grossa & $\begin{array}{l}\text { Ensino de Ciências e } \\
\text { Tecnologia (PPGECT) }\end{array}$ & (D) & 4 \\
\hline UEPG & Ponta Grossa & $\begin{array}{c}\text { Ensino de Ciências e } \\
\text { Educação Matemática } \\
\text { (PPGECEM) }\end{array}$ & $(\mathrm{M})$ & 3 \\
\hline UNESPAR & Paranavaí & $\begin{array}{c}\text { Formação Docente } \\
\text { Interdisciplinar (PPIFOR) }\end{array}$ & (M) & 3 \\
\hline \multicolumn{5}{|c|}{ PROGRAMAS PROFISSIONAIS } \\
\hline UTFPR & Ponta Grossa & $\begin{array}{c}\text { Ensino de Ciências e } \\
\text { Tecnologia (PPGECT) }\end{array}$ & (M) & 5 \\
\hline UTFPR & Curitiba & $\begin{array}{c}\text { Formação Científica, } \\
\text { Educacional e Tecnológica } \\
\text { (PPGFCET) }\end{array}$ & $(\mathrm{M} / \mathrm{D})$ & 4 \\
\hline UTFPR & Londrina & $\begin{array}{c}\text { Ensino de Ciências Humanas, } \\
\text { Sociais e da Natureza } \\
\text { (PPGEN) }\end{array}$ & (M) & 4 \\
\hline UENP & Cornélio Procópio & Ensino (PPGEN) & (M) & 3 \\
\hline UNICENTRO & Guarapuava & $\begin{array}{l}\text { Ensino de Ciências Naturais e } \\
\text { Matemática (PPGEN) }\end{array}$ & (M) & 3 \\
\hline
\end{tabular}

Fonte: os autores, com dados extraídos do resultado da Plataforma Sucupira.

Os programas acadêmicos existem nos níveis de mestrado e doutorado, o mesmo que se segue nos programas profissionais ${ }^{7}$. As diferenças entre as duas modalidades estão nos objetivos para preparar os agentes e, no caso do acadêmico, configura-se na formação do pesquisador e docente universitário, enquanto na modalidade profissional destina-se, principalmente, aos professores em serviço na Educação Básica, que dedicam-se a construir produtos educacionais disponibilizados nos sites dos programas para utilizarem em seu campo de trabalho e em outras escolas do país, bem como os produtos acadêmicos gerados do relato descritivo e analítico dessas experiências (CAPES, 2017a).

${ }^{7}$ A CAPES publicou no Diário Oficial da União (DOU) a Portaria n ${ }^{\circ}$ 60, de 20 de março de 2019, que atualiza a regulamentação sobre mestrado e doutorado profissionais. Anteriormente, cursos profissionais eram regulados pela portaria n ${ }^{\circ} 131$ de 28 de junho de 2017 que, a partir da nova publicação, deixou de vigorar.
(C) Rev. Inter. Educ. Sup.
Campinas, SP
$\mathrm{v} .7$
$1-28$
e021014 2021 
Além do estado do Paraná, São Paulo tem o segundo maior percentual na formação acadêmica dos agentes da Educação Química no estado do Paraná (Gráfico 8), distribuídas entres as graduações $(27,2 \%)$, as especializações $(10,9 \%)$, os mestrados $(27,2 \%)$ e os doutorados $(34,7 \%)$.

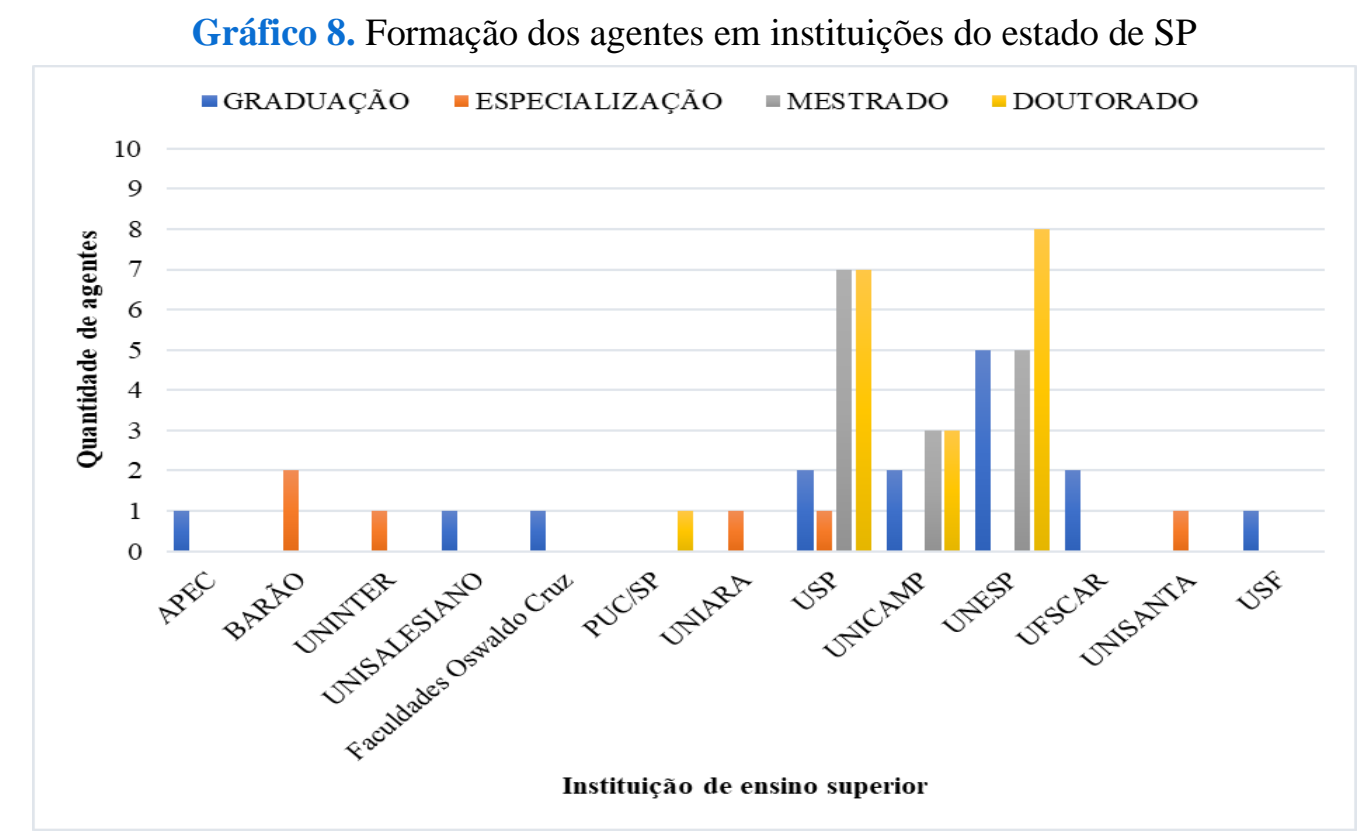

Fonte: os autores, com base nos dados dos currículos Lattes dos agentes da EQ

Das instituições em destaque na formação dos agentes em nível de mestrado e doutorado estão a: Universidade de São Paulo (USP), Universidade Estadual de Campinas (UNICAMP) e Universidade Estadual Paulista (UNESP). Isto se deve ao fato de que IES possuem programas de pós-graduação na Área de Ensino, responsáveis pela formação de professores universitários para o Ensino de Ciências/Química vinculados a sua gama de cursos, como 'Ensino de Ciências (Modalidades Física, Química e Biologia)' na USP e 'Educação para a Ciência' na UNESP de Bauru como nota 5 para mestrado e doutorado. 'Multiunidades em Ensino de Ciências e Matemática na UNICAMP também são exemplos da menção à formação de docentes em Química, com nota 4 para mestrado e doutorado, todos na modalidade acadêmico (CAPES, 2017).

Já nos estados de Santa Catarina e Rio Grande do Sul (Gráfico 9), os dados indicam uma menor representatividade na formação dos professores universitários do Paraná. No entanto, tais instituições possuem programas com boas avaliações pela CAPES, como o programa de 'Educação Científica e Tecnológica' da Universidade Federal de Santa Catarina (UFSC) em Santa Catarina, com nota 5, seguido do programa de 'Educação em Ciências Química da Vida e Saúde'(UFRGS) no Rio Grande do Sul, com nota 4, ambos para mestrado e doutorado acadêmico. 
Gráfico 9. Formação dos agentes em instituições dos estados de RS e SC

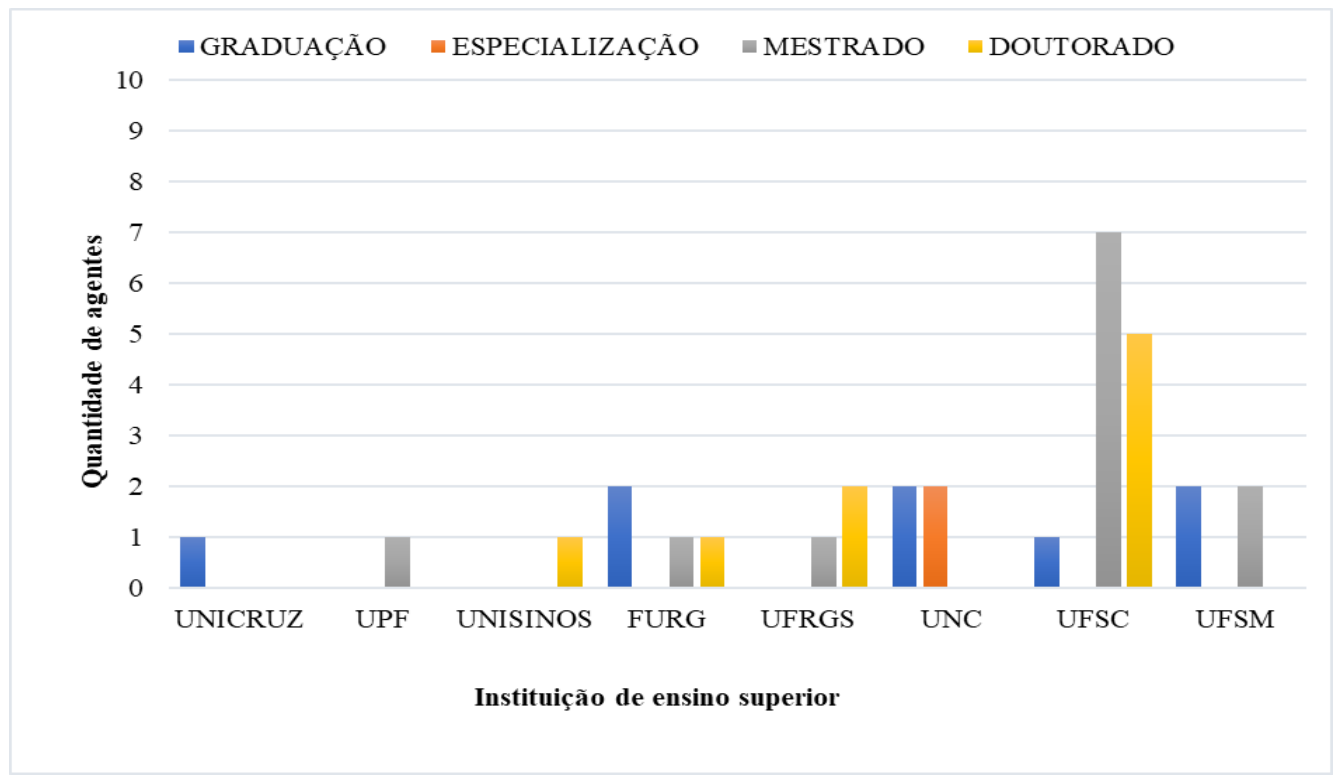

Fonte: os autores, com base nos dados dos currículos Lattes dos agentes da EQ

A justificativa da menor representatividade dos agentes formados neste estado, não deve estar associada a inexistência de programas com boas avaliações, no entanto as IES, possivelmente, nestes estados tenham conseguido abrir processos de seleção para manter seus agentes formados em seus próprios campos acadêmicos. O que evidencia que, os agentes, ao adentrarem no campo acadêmico durante seus mestrados e doutorados, criam vínculos profissionais naquele espaço, por sua dedicação a grupos de pesquisas, eventos regionais, bancas de seleção e criam seu capital social, em forma de reconhecimento de outros pares.

Por fim, no Gráfico 10, identificou-se outros agentes que, em uma quantidade menor, formaram-se na graduação em universidades como a Universidade Federal de Goiás (UFG), a Universidade Federal de Uberlândia (UFU), a Universidade Federal da Paraíba (UFPB), a Universidade Federal de Pernambuco (UFPE), a Universidade Federal do Rio de Janeiro (UFRJ). Já para os programas de pós-graduação, a formação deu-se em nível de mestrado na UFG, UFPB, Universidade Federal Rural de Pernambuco (UFRPE) e no doutorado na UFPE, UFRPE. Os dados apontam que os agentes não mantiveram um percurso linear para adentrar ao campo, como, por exemplo, o agente formado na UFPE, o qual se dedicou a formação acadêmica na área de Química. 
Gráfico 10. Formação dos agentes em instituições nos demais estados.

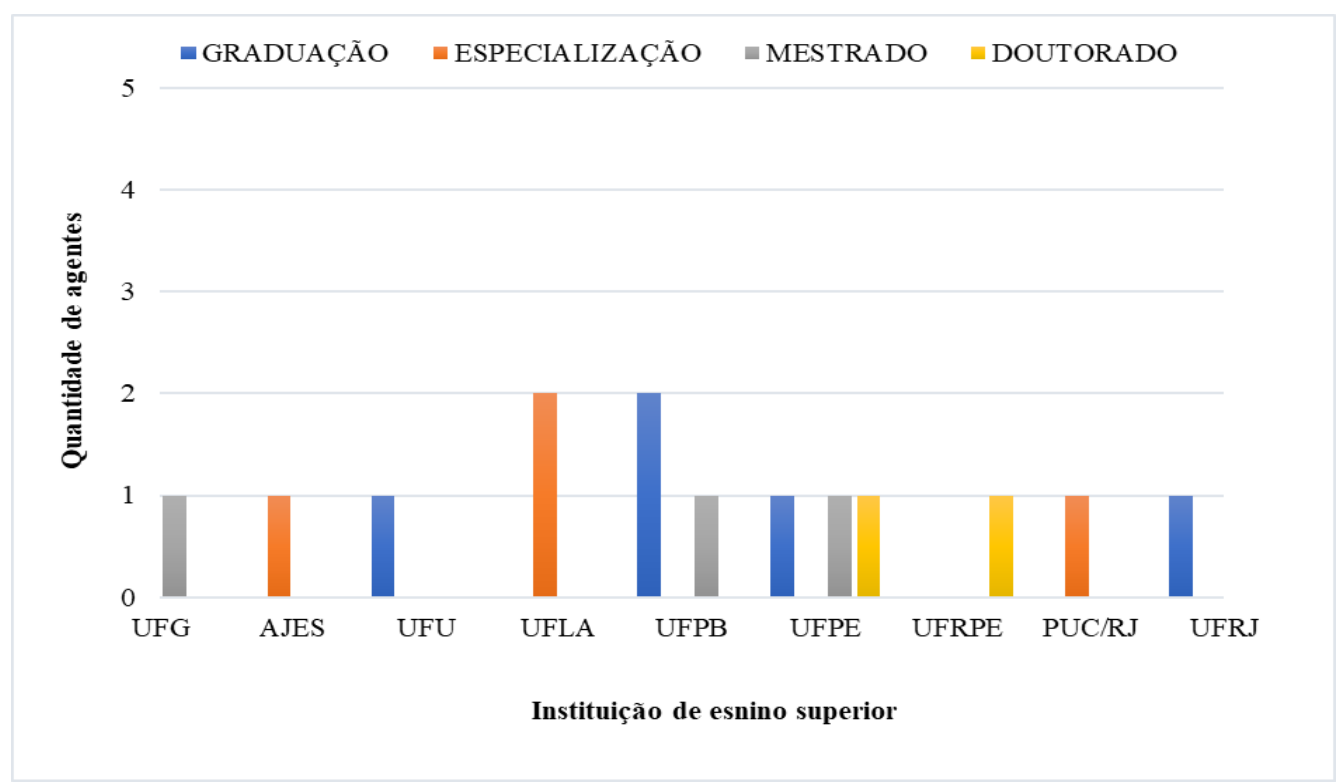

Fonte: os autores, com base nos dados dos currículos Lattes dos agentes da EQ

Os dados apontam que os agentes não mantiveram um percurso linear para adentrar ao campo, como por exemplo, o agente formado na UFPE, o qual se dedicou à formação acadêmica na área de Química, e hoje atua na área de Educação Química. Outro professor universitário iniciou sua formação no estado do Rio de Janeiro, indo fazer mestrado na área de Química, no estado de São Paulo, até chegar a fazer parte do campo acadêmico do estado do Paraná, e ingressar no subcampo da Educação Química na UEM. Este agente faz parte de um dos muitos exemplos de percursos para adentrar ao campo. Já outros iniciaram a sua trajetória no estado de SC, mas a inexistência de cursos de pós-graduação na área na IES em que realizava a graduação naquela época, condicionou-o a buscar formação no estado de São Paulo.

Estas situações descritas indicam que as formas de ingresso ao subcampo da Educação Química nem sempre ocorrem de forma linear depois de cursada a graduação em Licenciatura em Química e buscar os programas de pós-graduação em Ensino de Ciências. Até porque, o surgimento dos programas de pós-graduação da área de Ensino de Ciências e Matemática (Área 46) teve suas ampliações, desde as apresentações dos relatórios da área em 2010, com o crescimento de 7 programas em 2000 para 60 programas em 2010 (CAPES, 2010). Sendo este crescimento cada vez maior, visto que em 2013, após o remanejamento, agora dentro da área de 'Ensino', havia 104 programas, chegando a 157 no último relatório da em 2017, e a 181 programas indicados no documento de área (CAPES, 2019).

Diante disso, o estudo das formações acadêmicas dos agentes, ainda permitiu evidenciar as diferentes instituições para formação intelectual, uma vez que os ambientes de produção acadêmica e de sua circulação durante sua formação, contribuíram para aferir suas disposições acadêmicas, ou melhor, construir seu capital cultural, provenientes da concepções sobre a atribuição da atividade acadêmica (HEY, 2008). Neste sentido, os agentes têm o 
capital cultural incorporado, atribuído pela sua dedicação própria durante longo tempo, para apropriar-se de habitus, integrado pelas experiências diversas, funcionando "a cada momento como uma matriz de percepções, apreciações e ações” (BOURDIEU,1983, p. 65).

Com isso, o fato da formação dos agentes provenientes de outros estados, círculos de pesquisadores, proposta de trabalhos diferenciadas e concepções de ensino e pesquisa diversas; podem agregar àquele campo disposições geradas nos espaços do quais participaram, servindo, segundo Hey (2008), como meios de transformação, decorrentes de batalhas estabelecidas pela entrada de agentes com diferentes disposições vivenciadas na formação acadêmica.

\section{Período de Formação}

$\mathrm{Na}$ análise do Gráfico 11, pode-se identificar a quantidade de formações dos agentes em diferentes períodos. No caso de graduações, nota-se que os agentes fizeram mais de uma graduação, totalizando 74 graduações, entre elas: Química, Filosofia, Pedagogia, Matemática, Física e Biologia, ou seja, dos 62 professores universitários, 19,35\% deles fizeram pelo menos duas graduações.

Gráfico 11. Período de formação dos agentes do campo acadêmico da EQ.

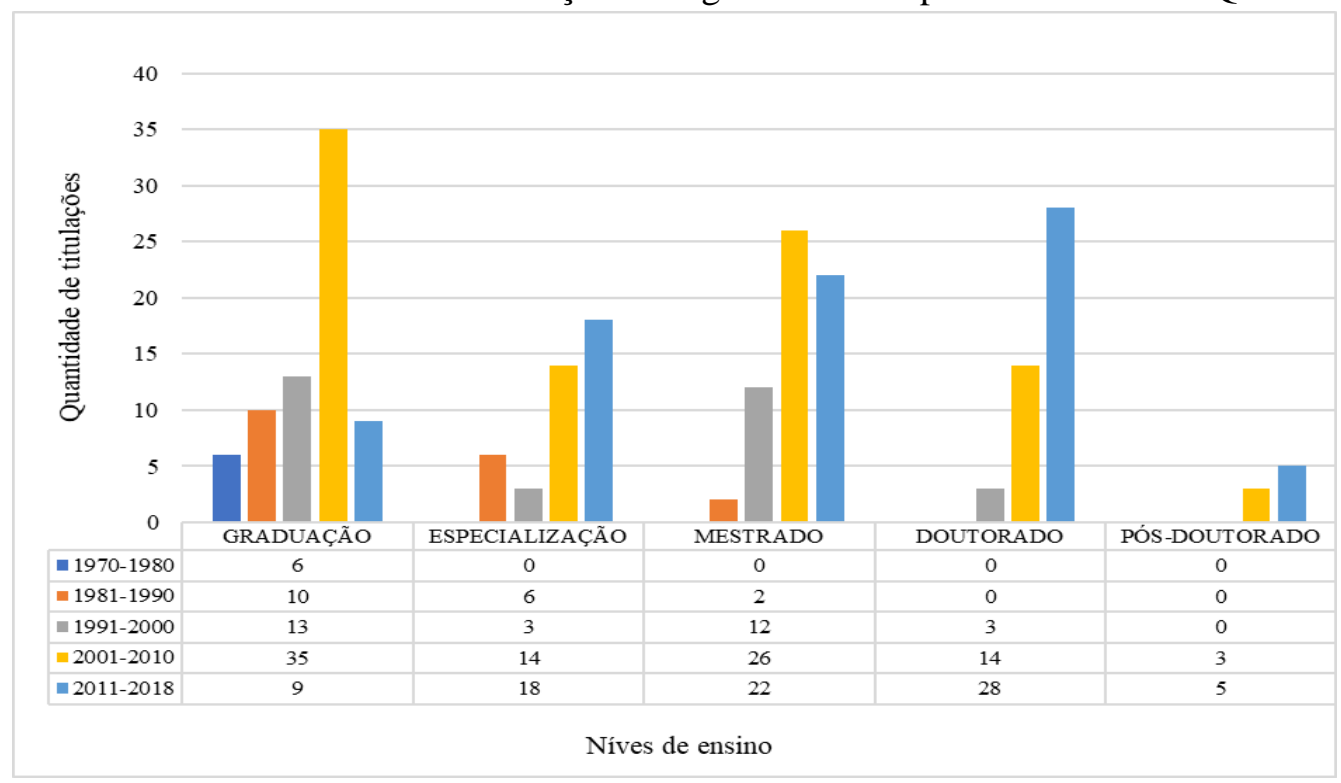

Fonte: os autores, com base nos dados dos currículos Lattes dos agentes da EQ

Há apenas 4 agentes do campo da EQ formados em graduações no período de 19701980, com nenhuma formação em programas de pós-graduações lato sensu e stricto sensu. As seis formações distribuem-se em: Licenciatura e Bacharelado em Química (1970-1973) na Pontifícia Universidade Católica (PUC) do Paraná; Licenciatura em Química (1971-1974) na PUC do Paraná; Graduação em Ciências de Primeiro Grau (1970-1972) na UNESPAR; Graduação em Química (1974-1977) na UEM; Licenciatura em Ciências (1974-1976) na UEM e Graduação em Habilitação em Química (1976-1978) na Associação Prudentina de Educação e Cultura de Presidente Prudente (APEC). Neste momento, nota-se que os professores naquela época formavam nos cursos de Ciências para depois buscar uma Habilitação em Química. 
O ingresso dos dois primeiros agentes no mestrado aconteceu no período de 19811990, com um agente no ano de 1986 na área de Físico-Química na Universidade de São Paulo (USP) e outro no ano de 1987 no Mestrado em Educação na Universidade Federal de Santa Catarina (UFSC). Sendo, estes professores, hoje atuantes nos cursos de Licenciatura em Química no campo acadêmico da área de EQ no estado do Paraná, UEM e UNESPAR, respectivamente, dentro do período de levantamento dos dados desta pesquisa.

Já no período de 1991-2000 observa-se o crescimento modesto no número de graduados (13). Entretanto, há um grande salto no índice de agentes sociais com titulações em nível de Mestrado (12), o que se dá pela busca de aperfeiçoamento na área. Sendo que, a formação de doutores (3) naquela época ainda se mostra incipiente.

Ao olhar para o recorte temporal de 2001-2010, a quantidade de graduados tem uma melhor representatividade se comparado com outros períodos. Sendo que, alguns destes agentes sociais graduados estiveram nos cursos de Licenciatura em Química após 2008 e 2009, depois da Resolução do CNE/CP no 2/2002 que implementou o aumento da carga horária dedicado ao estágio supervisionado e as atividades formativas, configurando-se como uma forma de identificação dos agentes com o ensino de Química. Outra justificativa atribuída pelo aumento de mestre pode estar associada ao surgimento de políticas públicas financiadas pela CAPES, como o PIBID inaugurado pela portaria normativa $n^{\circ} 38 / 2007$, as quais contribuíram para a inserção dos agentes, nas investigações no Ensino de Química, e consequentemente, a sua busca por programas de pós-graduação, pela sua identificação enquanto agente pesquisador neste campo científico.

Em relação ao período 2011-2018, nota-se que há uma redução no número de mestres, o que talvez seja um indicativo de que o campo começa a estabilizar em número de agentes participantes do subcampo da Educação Química. O aumento exponencial de doutorados pode indicar duas coisas: 1) concursos e testes seletivos mais criteriosos, exigindo a conclusão do curso para contração; 2) necessidade de especialização na carreira para manterse no campo. Sendo esta segunda, diretamente ligada às próprias forças do campo para manter suas ideias e critérios, podendo assim adentrar e manter-se ao campo, e nele adquirir reconhecimento e formas de pertencimento por meio dos diferentes volumes de capitais constituídos (BOURDIEU, 2004).

Com isso, os dados evidenciam que os agentes atuantes no subcampo da Educação Química no Paraná são provenientes de formações recentes, tendo a sua maior parte formação entre 2001-2010, e suas pós-graduações neste mesmo período se estendendo até 2018. No caso de doutores, observa-se que o campo é constituído por recém-doutores em uma faixa de 5 a 10 anos, principalmente quando se olha para o recorte 2011-2018. Tais dados estão de acordo com os dados publicados no relatório da CAPES (2017), que mostram o crescente número de egressos na área de 'Ensino' no período de 2000 a 2016, apontando para o aumento da demanda aos cursos de pós-graduação e o ritmo de crescimento da área de Ensino. 
Além disso, a posse deste capital escolar lhes proporciona uma posição social dominante, entre outros campos, "como detentores de uma forma institucionalizada de capital cultural, que lhe assegura uma carreira burocrática e rendimentos regulares" (BOURDIEU, 2017b, p.63), legitimados pelo reconhecimento que o cargo lhes confere.

Logo, no que se refere especificamente, a trajetória de formação descrita pelos seus determinantes escolares, nota-se que aspectos diferenciadores da formação, como cursar universidade em instituições públicas ou privadas, formar-se em áreas diferentes a de atuação ou sempre de maneira linear, participar de programas de pós-graduações com melhores avaliações ou piores, alternar-se entre outros estados durante a formação ou manter sempre dentro da mesma IES, estar no campo desde o início de sua constituição ou chegar nele já consolidado, podendo atribuir-se a diferentes posições destes sujeitos na estrutura do campo acadêmico. Entretanto os primeiros resultados ainda não conseguem apontar para tais posições especificamente ao estado do Paraná, visto que as discussões sobre os capitais simbólicos ainda não contemplam este trabalho, embora sabe-se os capitais não atuam de forma isoladas, e sim coexistem e atuam na representatividade, ou melhor, na posição do sujeito naquele campo.

\section{Considerações Finais}

Considerando o objetivo deste trabalho, de caracterizar o capital cultural no estado institucionalizado dos professores universitários da área de Educação Química no estado do Paraná, evidenciando a trajetória de formação acadêmica dos agentes por meio de seus indicadores escolares, fizemos a análise do nível de formação dos agentes, em relação a área de formação na pós-graduação, local e período.

Por esta trajetória identificou-se um campo sendo estruturado, em sua maioria, por mestres $(100 \%)$ e doutores $(91,9 \%)$, visto que as certificações de especializações lato sensu $(45,2 \%)$ e pós-doutorado $(12,9 \%)$ não têm sido requisitos mínimos de contratação nos concursos e processos de seleção. Suas formações ocorreram, principalmente, nas IES no estado do Paraná (52,2\%), com grandes influências em espaços de pós-graduação stricto sensu, nos estados de São Paulo (30\%) e Santa Catarina (12\%), devido a representatividade e longevidade dos cursos e programas. A busca pelas certificações nestas IES públicas, nos níveis de mestrado e doutorado, pode indicar a tentativa de organização dos agentes para alcançar suas posições de destaque, no que concerne seu capital cultural institucionalizado, ao apropriar-se da representatividade daquele campo acadêmico.

Entretanto, a trajetória nestes níveis (mestrado e doutorado) de formações nem sempre se mostram lineares, devido às mudanças de áreas em algum momento do percurso traçado, como por exemplo, a saída do mestrado em uma determinada área, e sua continuidade no doutorado na área de área de Ensino. A mudança para a área de Ensino pode estar condicionada à preocupação dos agentes em buscar uma formação acadêmica específica, enquanto objeto de investigação comum e agrega-se poderes simbólicos para atribuições de posições dos sujeitos no campo acadêmico ainda não perceptível no resultado deste trabalho.

\begin{tabular}{l|l|l|l|l|l|}
\hline C) Rev. Inter. Educ. Sup. & Campinas, SP & v.7 & $1-28$ & $\mathrm{e} 021014$ & 2021 \\
\hline
\end{tabular}


Além disso, a trajetória na formação dos agentes nos mostra, um subcampo da Educação Química nas IES no estado do Paraná, ainda é recente, sendo constituído em sua maioria por agentes formados nas últimas duas décadas, com crescente número de egresso da área de Ensino, decorrente das adequações curriculares às regulamentações da área de formação de professores (Resolução do CNE/CP $n^{\circ}$ 2/2002) nos cursos de Licenciatura em Química. Os mesmos contribuem para a contratação de profissionais com formações específicas na área, priorizando pré-requisitos para a seleção e contratação de agentes sociais neste campo acadêmico.

Por tratar-se de um campo recente, ainda existe um percentual de professores universitários com formações em outra área do conhecimento e que são atuantes no subcampo da EQ. Esta diversidade de formações pode estar associada à necessidade destes profissionais, em algum momento, terem se dedicado e assumido a área de ensino, quando ainda não existiam agentes com formações específicas. Todavia esta diversidade também está relacionada à formação não linear dos agentes durante a sua trajetória de formação, visto que, o interesse pela área pode ter surgido de experiências profissionais ao longo da docência universitária, relações com grupos de pesquisa e extensão, participações em eventos, conhecimento de políticas públicas, dentre outros.

Os programas de pós-graduação têm figurado como elementos importantes para crescimento da área, visto que, muitos dos agentes formados nestes espaços estão inseridos nos cursos de Licenciatura em Química, sejam eles concursados ou colaboradores/temporários. Além disso, as avaliações dos programas de pós-graduação como PECEM da UEL, têm contribuído para o reconhecimento e para a representatividade, em nível nacional, das lutas e forças estabelecidas dentro do campo do Ensino de Ciências e Matemática no Estado do Paraná.

Apesar dos resultados deste trabalho não conseguirem indicar ainda as estruturações do campo acadêmico pela posição dos agentes por faltar, nesta análise olhar para outros capitais simbólicos, entendemos que trilhar a trajetória destes agentes possibilita compreender que os indicadores escolares configura-se como elementos influenciadores na agregação de capital cultural, principalmente no seu estado institucionalizado, que confere, pela certificação, uma forma de objetivação do capital cultural daquele subcampo (Educação Química), incorporado de disposições durante sua trajetória de formação acadêmica.

\section{Referências}

BARDIN, Laurence. Análise de conteúdo. 4. ed. Lisboa: Edições 70, 2010.

BRASIL. Lei $\mathbf{n}^{\mathbf{0}} \mathbf{1 1 . 1 8 4}$ de 7 de outubro de 2005. Dispõe sobre a transformação do Centro Federal de Educação Tecnológica do Paraná em Universidades Tecnológicas Federal do Paraná e dá outras providências. Brasília, DF: Senado Federal, 2005. 
BRASIL. Portaria Normativa no 38, de dezembro de 2007. Dispõe sobre o Programa Institucional de Bolsa de Iniciação à Docência - PIBID. Diário Oficial da União, n.239, seção 1, p.39, 2007.

BRASIL. Resolução CNE/CP n 2, de 19 de fevereiro de 2002. Institui a duração e a carga horária dos cursos de licenciatura, de graduação plena, de formação de professores da Educação Básica em nível superior. 2002, 1p.

BRASIL. Portaria Normativa $n^{0}$ 122, de 16 de setembro de 2009. Dispõe sobre o Programa Institucional de Bolsa de Iniciação à Docência, no âmbito da CAPES. Diário Oficial da União, 2009.

BOURDIEU, Pierre. Esboço de uma teoria da prática. In: ORTIZ, Renato (Org.). Pierre Bourdieu: Sociologia. 2.ed. São Paulo: Ática, 1983. p. 46-81.

BOURDIEU, Pierre. O uso das ciências sociais: Por uma sociologia clínica do campo científico. Tradução Denice Barbara Catani. São Paulo: Editora UNESP, 2004, 86p. BOURDIEU, Pierre. Os três estados do capital cultural. In: Maria Alice e Afrânio Catani (org.). Escritos de Educação. Petrópolis, RJ: Vozes, p. 71-79, 2007.

BOURDIEU, Pierre. Para uma sociologia da Ciência. Portugal: Edição 70, 2017a, 166p.

BOURDIEU, Pierre. Homo academicus. 2.ed. Tradução Ione Ribeiro Valle, Nilton Valle. Florianópolis: Ed. as UFSC, 2017b.

CAPES. Coordenação de Aperfeiçoamento de Pessoal de Nível Superior. Ministério da Educação (MEC). Documento de área: área 46, Ensino. 2019.

CAPES. Coordenação de Aperfeiçoamento de Pessoal de Nível Superior. Ministério da Educação (MEC). Documento de área: área 46, Ensino. 2017a.

CAPES. Coordenação de Aperfeiçoamento de Pessoal de Nível Superior. Ministério da Educação (MEC). Relatório de Avaliação 2013-2016: área 46, Ensino. 2017 b.

HEY, Ana Paula. Esboço de uma sociologia do campo acadêmico: a educação Superior no Brasil. São Carlos: EdUFSCar, 2008, 177p.

MASSI, L. CARVAHO, H. GIORDAN, M. Perfil socioformativo dos orientadores, heterogeneidade e hierarquia social na área de Ensino da Capes. Revista Investigação em Ensino de Ciências, Rio Grande do Sul, v. 25, n.1, p.421-432, 2020. Disponível em: https://www.if.ufrgs.br/cref/ojs/index.php/ienci/article/view/1785. Acesso em: 14 mai. 2020.

MONTAGNER. Miguel Angêlo. Trajetória e biografias: notas para uma análise bourdieusina. Sociologia. Porto Alegre, ano 9, n.17, p.240-264, 2007. Disponível em: https://www.scielo.br/pdf/soc/n17/a10n17.pdf. Acesso em: 13 mai. 2020.

OLIVEIRA, Maria Marly de. Como fazer pesquisa qualitativa, 6.ed. Petrópolis, RJ: Vozes, 2014. 
SCHNETZLER, Roseli Pacheco. A pesquisa em ensino de Química no Brasil: conquistas e perspectivas. Química Nova, São Paulo, v.25, supl.1, p. 14-24, 2002. Disponível em:

https://www.scielo.br/pdf/qn/v25s1/9408.pdf. Acesso em: 13 mai. 2020. 